Portland State University

PDXScholar

Fall 1-16-2014

\title{
Impact of Sustainable Cool Roof Technology on Building Energy Consumption
}

Prem Kiran Vuppuluri

Portland State University

Follow this and additional works at: https://pdxscholar.library.pdx.edu/open_access_etds

Part of the Architectural Technology Commons, and the Construction Engineering Commons Let us know how access to this document benefits you.

Recommended Citation

Vuppuluri, Prem Kiran, "Impact of Sustainable Cool Roof Technology on Building Energy Consumption" (2014). Dissertations and Theses. Paper 1530.

https://doi.org/10.15760/etd.1529

This Thesis is brought to you for free and open access. It has been accepted for inclusion in Dissertations and Theses by an authorized administrator of PDXScholar. Please contact us if we can make this document more accessible: pdxscholar@pdx.edu. 
Impact of Sustainable Cool Roof Technology on Building Energy Consumption

by

Prem Kiran Vuppuluri

A thesis submitted in partial fulfillment of the requirements for the degree of

\author{
Master of Science \\ In \\ Mechanical Engineering
}

Thesis Committee:

Dr. David Sailor (Chair)

Dr. Huafen $\mathrm{Hu}$

Dr. Graig Spolek

Portland State University

2013 


\begin{abstract}
:
Highly reflective roofing systems have been analyzed over several decades to evaluate their ability to meet sustainability goals, including reducing building energy consumption and mitigating the urban heat island. Studies have isolated and evaluated the effects of climate, surface reflectivity, and roof insulation on energy savings, thermal load mitigation and also ameliorating the urban heat island. Other sustainable roofing systems, like green-roofs and solar panels have been similarly evaluated. The motivation for the present study is twofold: the first goal is to present a method for simultaneous evaluation and inter-comparison of multiple roofing systems, and the second goal is to quantitatively evaluate the realized heating and cooling energy savings associated with a white roof system compared to the reduction in roof-top heat flux.
\end{abstract}

To address the first research goal a field experiment was conducted at the International Harvester Building located in Portland, OR. Thermal data was collected for a white roof, vegetated roof, and a solar panel shaded vegetated roof, and the heat flux through these roofing systems was compared against a control patch of conventional dark roof membrane. The second research goal was accomplished using a building energy simulation program to determine the impact of roof area and roof insulation on the savings from a white roof, in both Portland and Phoenix. The ratio of cooling energy savings to roof heat flux reduction from replacing a dark roof with a white roof was 1:4 for the month of July, and 1:5 annually in Portland. The COP of the associated chillers ranges from 2.8-4.2, indicating that the ratio of cooling energy savings to heat flux reduction is not accounted for solely by the COP of the chillers. The results of the 
building simulation indicate that based on energy savings alone, white roofs are not an optimal choice for Portland. The benefits associated with cooling energy savings relative to a black roof are offset by the winter-time penalty, and the net benefit from adopting white roof technology in Portland is small. That said, there are other potential benefits of white roofing such as impact on urban heat islands and roof life that must also be considered. 
Table of Contents

Abstract............................................................. i

List of Tables................................................. iv

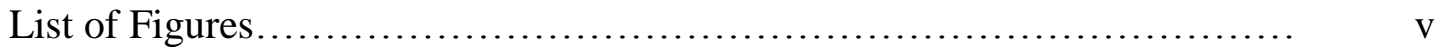

Chapter 1: Introduction ............................................ 1

1.1) Overview of Roofing Technologies ............. 3

1.2) Purpose of Study............................ 7

Chapter 2: Methods................................................ 9

2.1) Field Experiment........................... 9

2.2) Building Simulation......................... 13

Chapter 3: Results.............................................. 16

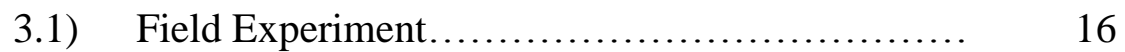

3.2) Building Simulation......................... 20

Chapter 4: Discussion........................................... 42

Chapter 5: Conclusions and Recommendations........................ 48

Chapter 6: References............................................................. 50 


\section{List of Tables:}

Table 1: Comprehensive list of thermal load mitigation and end use energy savings in $\mathrm{kWh} / \mathrm{m}^{2}$ for building simulation in Portland, OR.

Table 2: Ratio of Thermal Loads to Energy Use, for cooling reduction in July, annual cooling reduction and heating penalty. Building simulation conducted in Portland, OR.

Table 3: Comprehensive list of thermal load mitigation and end use energy savings in $\mathrm{kWh} / \mathrm{m}^{2}$ for building simulation in Phoenix, AZ.

Table 4: Ratio of Thermal Loads to Energy Use, for cooling reduction in July, annual cooling reduction and heating penalty. Building simulation conducted in Phoenix, AZ. 


\section{List of Figures:}

Figure 1: Pie Chart for Site Energy Consumption (taken from Buildings Energy Data Book) .......... 1 Figure 2: Commercial Sector Retail Energy Prices (obtained from Buildings Energy Data Book) ... 2 Figure 3: Energy balance diagram for dark (conventional) roof. $\mathrm{q}_{\mathrm{sw}}=$ short wave radiation from sun absorbed by surface. $\mathrm{q}_{\mathrm{Lw}}=$ long wave exchange between roof surface and surroundings ..... 3 Figure 4: Energy balance diagram for white (cool) roof. $\mathrm{q}_{\mathrm{sw}}=$ short wave radiation from sun absorbed by surface. $\mathrm{q}_{\mathrm{LW}}=$ long wave exchange between roof surface and surroundings

Figure 5: Energy balance diagram for vegetated (green) roof. $\mathrm{q}_{\mathrm{sw}}=$ short wave radiation from sun absorbed by surface. $q_{\mathrm{LW}}=$ long wave exchange between roof surface and surroundings.

Figure 6: Photographs of the side view of the international harvester (left) and a look at the solar PV array mounted on top of vegetated green-roof (right)

Figure 7: Side schematic showing placement of roof and ceiling thermocouples on the international harvester building

Figure 8: Temperature boundary data taken from July 5, 2012 to July 11, 2012 on the International Harvester roof....

Figure 9: Difference in heat flux between the dark roof and white roof surfaces taken over summer period of July 5-11, 2012

Figure 10: Temperature boundary data taken from International Harvester during winter (January 5, 2011-January 11, 2011)

Figure 11: Difference in heat flux between the dark roof and white roof surfaces taken over winter period of June 5-11, 2011

Figure 12: Difference in electricity consumed in July for cooling (dark roof simulation vs white roof simulation) plotted vs roof area. Simulation runs performed for roof insulation value of R-7, R-14, R-21, R-28 and R-35.

Figure 13: Difference in electricity consumed annually for cooling (dark roof simulation vs white roof simulation) plotted vs roof area. Simulation runs performed for roof insulation value of R-7,

R-14, R-21, R-28 and R-35.

Figure 14: Difference in natural gas consumed annually for heating (dark roof simulation vs white roof simulation) plotted vs roof area. Simulation runs performed for roof insulation value of R-7, R-14, R-21, R-28 and R-35. Building simulation performed in Portland, OR.

Figure 15: Difference in electricity consumed for cooling per unit area in the month of July (dark roof simulation vs white roof simulation) plotted vs R-value (IP units). The vertical axis corresponds to the SI units of the slope of the energy consumption curves. Building simulation performed in Portland, OR

Figure 16: Difference in electricity consumed annually for cooling per unit area (dark roof simulation vs white roof simulation) plotted vs R-value (IP units). Building simulation performed in Portland, OR

Figure 17 Difference in natural gas consumed annually for heating per unit area (dark roof simulation vs white roof simulation) plotted vs R-value (IP units). Building simulation performed in Portland, OR 
Figure 18: Difference in roof-top cooling load contribution per unit area for July (dark roof simulation vs white roof simulation) plotted vs R-value (IP units). Building simulation performed in Portland, OR

Figure 19: Difference in annual roof-top cooling load contribution per unit area (dark roof simulation vs white roof simulation) plotted vs R-value (IP units). Building simulation performed in Portland, OR.

Figure 20: Difference in annual roof-top heating load contribution per unit area (dark roof simulation vs white roof simulation) plotted vs R-value (IP units). Building simulation performed in Portland, OR

Figure 21: : Difference in electricity consumed in July for cooling (dark roof simulation vs white roof simulation) plotted vs roof area. Simulation runs performed for roof insulation value of R-7, R-14, R-21, R-28 and R-35. Building Simulation performed in Phoenix, AZ.

Figure 22: Difference in electricity consumed annually for cooling (dark roof simulation vs white roof simulation) plotted vs roof area. Simulation runs performed for roof insulation value of R-7, R-14, R-21, R-28 and R-35.. Building simulation performed in Phoenix, AZ. 30

Figure 23: Net difference in annual heating energy use (dark roof simulation vs white roof simulation) plotted vs roof area. Simulation runs performed for roof insulation value of R-14, R21, R-28 and R-35. Building simulation performed in Phoenix, AZ.

Figure 24: Difference in electricity consumed for cooling per unit area in July (dark roof simulation vs white roof simulation) plotted vs R-value (IP units). Building simulation was performed in Phoenix, AZ.

Figure 25: Difference in electricity consumed annually for cooling per unit area (dark roof simulation vs white roof simulation) plotted vs R-value (IP units). Building simulation was performed in Phoenix, AZ.

Figure 26: Difference in natural gas consumed annually for heating per unit area (dark roof simulation vs white roof simulation) plotted vs R-value (IP units). Building simulation was performed in Phoenix, AZ.

Figure 27: Difference in roof-top cooling load contribution per unit area for July (dark roof simulation vs white roof simulation) plotted vs R-value (IP units). Building simulation was performed in Phoenix, AZ.

Figure 28: Difference in annual roof-top cooling load contribution per unit area (dark roof simulation vs white roof simulation) plotted vs R-value (IP units). Building simulation was performed in Phoenix, AZ.

Figure 29: Difference in annual roof-top heating load contribution per unit area (dark roof simulation vs white roof simulation) plotted vs R-value (IP units). Building simulation was performed in Phoenix, AZ. 


\section{Chapter 1: Introduction}

In the building sector, sustainable engineering practices usually focus upon reducing total energy consumption. According to the 2011 Buildings Data Book[1] published by the US Department of Energy, the US consumed 97.8 quadrillion BTU's of energy in 2010, representing $19 \%$ of global consumption of energy. The US buildings sector alone accounted for $7 \%$ of primary energy consumption across the entire planet, and $41 \%$ of total energy consumption in the United States. Electricity was $72.9 \%$ of the energy consumed in 2010 by the US buildings sector[2]. Coupled with the pie chart distribution shown in Figure 1 for end uses, it is clear that significant improvements must be performed to lower the energy requirement of some of these end uses (space heating, space cooling, lighting, etc.) in order to reduce the total energy consumption by the building sector. An average building in the US expends $12 \%$ of its energy on cooling[2], but in warmer climates, the energy demand for cooling will be higher[3].

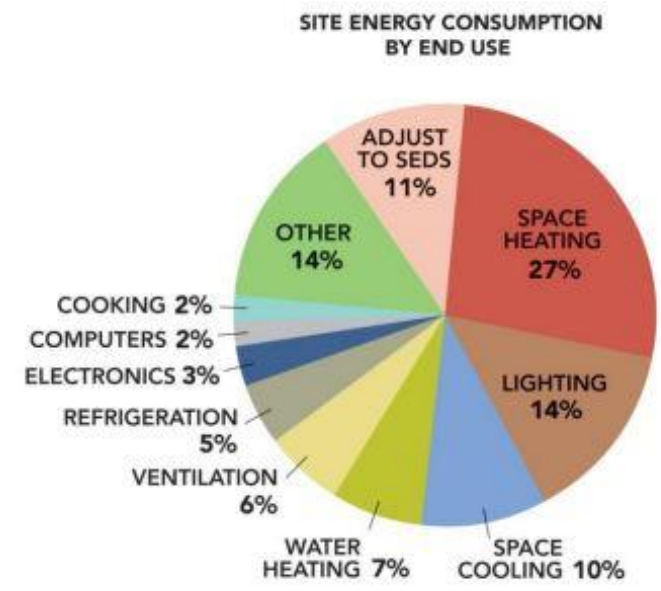

Figure 1: Pie Chart for Site Energy Consumption (taken from Buildings Energy Data Book) 
The price of electricity is still the higher than any other energy source, according to Figure 2(also from the Building Energy Data Book).

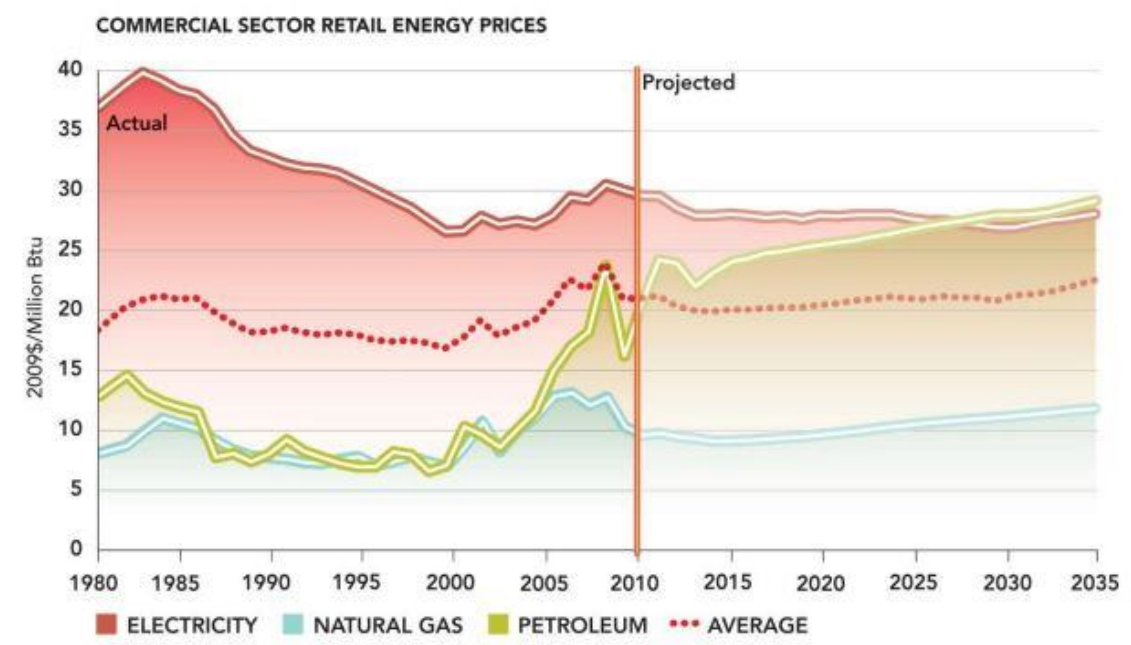

Figure 2: Commercial Sector Retail Energy Prices (obtained from Buildings Energy Data Book)

Technologies that mitigate the consumption of energy by buildings are generally focused on changes to the building envelope, the HVAC system or lighting of the building. Most research on improving the building envelope is either focused on some form of superinsulation or a roofing technology (such as cool roofs, green roofs and solar). Improvements to the HVAC system include the use of heat recovery ventilation (HRV), geothermal heat pumps, and solar water collectors. Lighting can also be improved to decrease energy consumption by adopting daylighting, or by using energy efficient artificial lighting such as LED. Some of the technologies mentioned above can affect multiple sectors of the energy consumption pie chart (Figure 1). In the case of roofing technologies such as cool roofs, green roofs and solar panel systems, the primary application to building energy balances is to learn how they affect the conduction heat 
flux through the roof, because this heat flux can impact heating loads (in winter) or cooling loads (in summer).

\section{1) Overview of Roofing Technologies}

Roof surfaces comprise a large fraction of the urban landscape[7]. Consequently, urban sustainability leaders are increasingly turning to roofing technologies to achieve a range of goals. These include generating electricity, reducing building energy consumption, ameliorating the urban heat island (UHI) and reducing storm-water runoff. Specific technologies of interest include highly reflective membranes, vegetated green roofs, and solar panels (photovoltaic and thermal). Each technology has its own proponents and advocates, and they are often competing for the same real estate.

Conventional roofs, or dark asphalt roofs are characterized as having a low albedo (surface reflectivity), usually on the order of 0.1 or less. These roofs typically reflect a small fraction of incoming short-wave radiation, which makes them poorly suited for summer-time conditions. Figure 3 shows the major sources of heat flux associated with the dark roof energy balance:

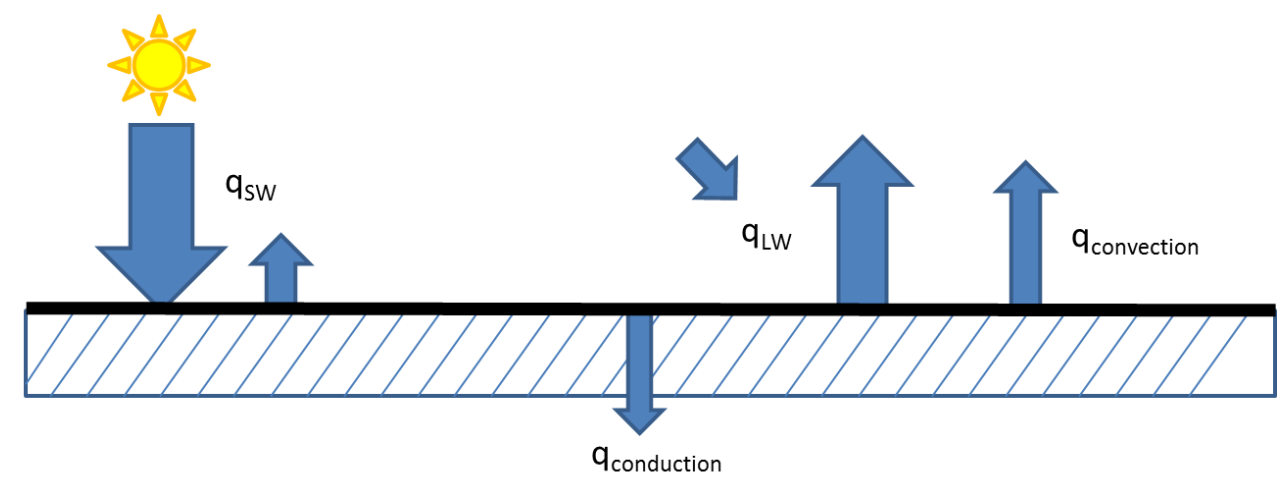

Figure 3: Energy balance diagram for dark (conventional) roof. $q_{\mathrm{sw}}=$ short wave radiation from sun absorbed by surface. $q_{L W}=$ long wave exchange between roof surface and surroundings 
The energy balance is driven by incoming short-wave radiation from the sun. Because of the low albedo of the roof, a very small fraction is reflected, and the majority is absorbed. Some of this radiation is re-radiated as long wave radiation, and also the heated surface of the roof drives convection to the surrounding air. The conduction heat flux into a building with a dark roof is large relative to conduction heat flux from other roofing systems because of the very small quantity of reflected short wave radiation. The total contribution, however, can be very small to total heat load contributions for well insulated roofs.

Cool roof technology has been the subject of numerous prior studies that have attempted to evaluate its efficacy as a solution to saving building energy $[5,6]$, as well as a strategy for heat island mitigation[4, 7]. Cool roofs are roofs with high solar reflectivity or "albedo", and they help reduce the roof surface temperature by absorbing a lower proportion of incoming short wave radiation than the more commonly used dark membrane roofs. While a typical dark membrane roof may have an albedo as low as 0.1 or 0.2 , a new cool roof may have an albedo as high as 0.8 . Of course, with aging the albedo of a typical cool roof may degrade substantially.

The rooftop energy balance for a cool roof is illustrated in Figure 4. As opposed to the dark roof, a cool roof is characterized primarily by the larger amount of reflected short-wave radiation. As noted above, this is primarily due to the increased reflectivity (albedo) of the surface, and also drives changes to the long wave radiation exchange, the convection heat flux from the roof, and conduction heat flux into the building. Due to the high albedo of white roofs, they can help mitigate the urban heat island effect by reducing 
the amount of convection heat flux from the roof due to lowered surface temperatures, and also, white roofs are known to reduce the cooling loads in the summer-time.

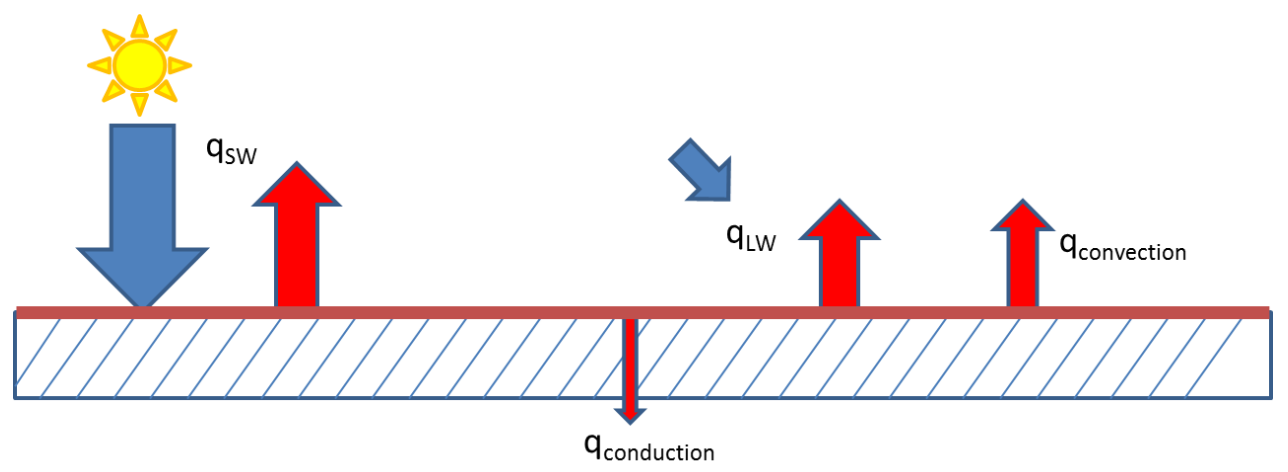

Figure 4: Energy balance diagram for white (cool) roof. $\mathrm{q}_{\mathrm{sw}}=$ short wave radiation from sun absorbed by surface. $q_{\mathrm{LW}}=$ long wave exchange between roof surface and surroundings

Studies have a strong connection between roof albedo and building energy savings. For example, one study of cool roofs reported a peak summer surface temperature reduction of $35^{\circ} \mathrm{C}$ compared to conventional black membrane roofs[6]. Another study also reported peak power reduction of $0.6 \mathrm{~kW}$ for a building with a high albedo (0.73) roof as compared to a low albedo $(0.18)$ roof $[8]$. Over the years there have been many other studies that also focus on the potential building energy benefits of high roof albedo (e.g., [5-10]). Another consideration for evaluating reflective materials as roofing alternatives is their impact on the urban environment. This has been extensively studied and documented in a number of studies[11-13].

However, the benefits associated with the high solar reflectivity of white roofs during the summer periods are drawbacks during the winter season, as the increased amount of reflected short-wave radiation results in a heating penalty in winter[9].

A whole other line of research has focused on the potential energy savings associated with vegetated green roofs[14-19]. In one of the earliest studies of energy 
performance of green roofs, it was shown that green roofing has the potential to significantly reduce building energy consumption, but that the benefit is highly dependent upon the level of insulation[20]. In this study Niachou found heating and cooling energy savings as low as $2 \%$ for moderately well-insulated buildings and as large as $48 \%$ for uninsulated buildings. Of course, the same dependence on insulation holds true for the magnitude of energy savings associated with a high albedo (cool) roof.

The green roof energy balance is presented in Figure 5. The primary differences between the green roof and simple membrane technologies is the addition of the latent heat flux term, and the addition of thermal mass above the roof insulation layer. Much of the incoming short wave radiation $(\sim 18-25 \%)$ is still reflected by the green roof, as it has a higher albedo than a dark membrane roof, but this is not the primary mode of performance for the green roof. The latent heat flux from a vegetated roof significantly dampens temperature fluctuations, and the thermal mass of the green roof can increase the lag time between the exterior and interior temperature profiles of the roof.

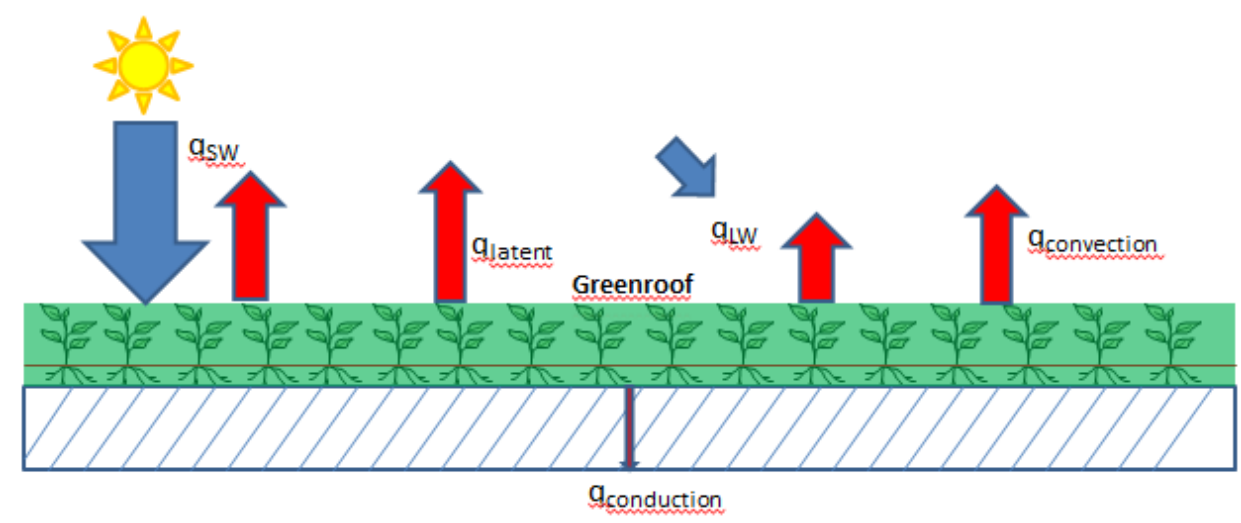

Figure 5: Energy balance diagram for vegetated (green) roof. $q_{\mathrm{sw}}=$ short wave radiation from sun absorbed by surface. $q_{L W}=$ long wave exchange between roof surface and surroundings. 
There has been much less research into the effects of photovoltaic technologies on the energy balance of building roofs, and such studies tend to focus on the urban environment rather than the building itself (e.g., [21, 22]). One recent study conducted by our research group presented a detailed analysis of the energy balance associated with rooftop mounted photovoltaics for cases where the underlying roof material was a black membrane, white membrane, or vegetated green roof. This study developed a model of the roof surface energy balance including the convective heat transfer and long wave radiation exchange at the surfaces of the panels themselves[23].

\section{2) Purpose of Study}

Prior studies have looked at building energy savings associated with implementing cool roofs as indicated above. Multiple studies have considered savings in space cooling associated with high reflectivity white roofs. One study in particular analyzed reduction in electrical energy consumption using a building simulation program and noted reductions in building energy consumption of $2.8-3.4 \%$ for a complete replacement cool roof[11]. In actual savings, they noted a reduction in electricity use of $24.9 \mathrm{kwh} / \mathrm{m}^{2}$ in Phoenix, AZ. A cost-benefit analysis of the analyzed roof system indicated a potential payback time of 9 years of the roof construction cost, with an estimated life-time of 20 years. Another study noted the impact of insulation on cooling load mitigation[24]: a simulation was performed for mild and hot climates, with absorbance varying from $0-1$, where the total energy load decreases by $32 \%$ and $47 \%$, for un-insulated buildings, and by $26 \%$ and $32 \%$ respectively for well-insulated buildings. Several other studies noted unique savings associated with various values of absorbance 
and reflectance of the building rooftops[25-29], and another study evaluated the impact of roof color on humid environments[30].

These studies noted savings as percentages and fractions of total energy expenditure, but there appeared to be no comprehensive, qualitative evaluation of the impact of roof insulation on the coupling of the external and internal environment, nor was there a clear comparison of rooftop cooling load reduction to realized energy savings. Another group took the winter-time heating penalty into account, and noted that even with this consideration, in most climates the cooling load reduction outweighs the heating load penalty[31].

The focus of this current study is on analyzing the impact of cool roofs on roof thermal loads (heat fluxes through the roof) and building energy consumption, using conventional dark roofs as a baseline for comparison. The research task is to determine what fraction of the cooling load reduction or heat load penalty associated with implementing a white roof in place of a dark roof actually results in a decrease in cooling energy use or increase in heating energy consumption. The primary factor involved in this analysis is performance of the HVAC system, which is characterized by the COP of the chiller or the efficiency of the heating coil and the thermostat schedules in the building. For every unit of roof heat flux reduced by switching from a dark roof to a white roof, only a fraction of that flux, possibly characterized by the COP of the HVAC system, is actually gained as an energy savings. To address this question, both an experimental analysis and a numerical simulation were undertaken. The results of this work are presented in the following chapters. 


\section{Chapter 2: Methods}

The main focus of this work is to present an approach of evaluating the energy savings associated with sustainable roofing systems. Much of the prior research in this field has focused on the performance of individual technologies in isolation (e.g., numerous green roof studies and cool roof studies) as discussed in the prior section. As a result, often times it is unclear whether the technology under study is being objectively compared against appropriate alternatives. To that end, experimental analysis and building simulation studies were carried out to isolate and quantify the impact of sustainable roofing systems on the energy budget of a well-insulated building.

\section{1) Field Experiment}

Experimental analysis was conducted at the International Harvester Building in Portland, Oregon, USA, shown in the photographs in Figure 6 below.

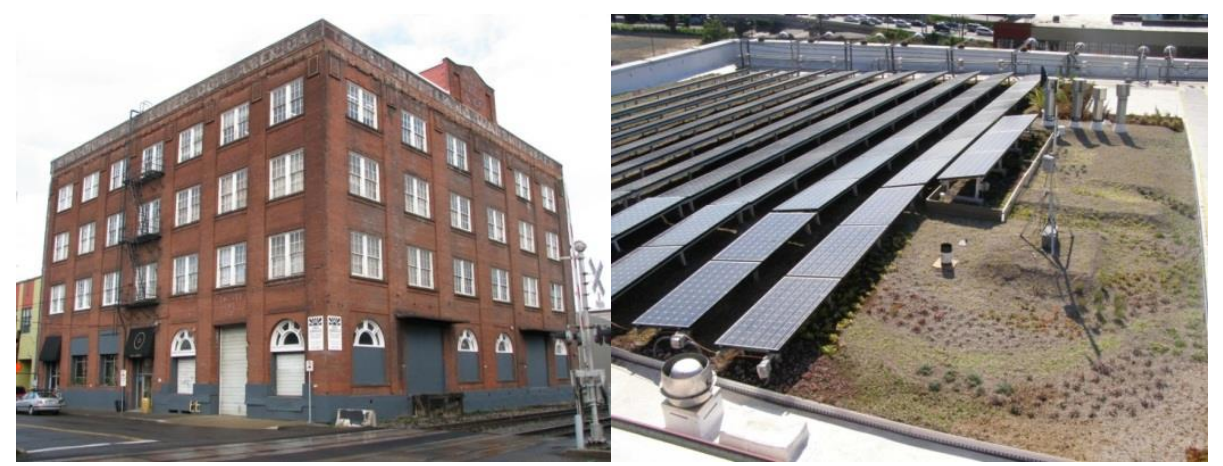

Figure 6: Photographs of the side view of the international harvester (left) and a look at the solar PV array mounted on top of vegetated green-roof (right)

This building was recently renovated in 2010, with new features implemented on the roof. These include installation of a 216 panel, $45.6 \mathrm{~kW}$ solar photovoltaic (PV) array combined with $576 \mathrm{~m}^{2}$ of vegetated roofing (sedum plantings in a nominally $6.5 \mathrm{~cm}$ thick 
growing media). This roof also features a small $0.75 \times 0.75 \mathrm{~m}^{2}$ area of black membrane, installed specifically as a control in the experimental study, and is surrounded by the aforementioned vegetated roofing and also white membrane. Both the black and white roof membranes are 80 mil thermoplastic polyolefin (TPO). The albedo of the white roof membrane was not measured, but per manufacturer's specifications, is 0.88 when new. As shown by Akbari[6], however, the albedo of weathered, high albedo membranes may decrease to 0.6 or lower. Thermocouples were placed on the roof surface at the center of four regions: the black test patch, an adjacent region with exposed white membrane, another region with exposed green roof, and a final section of green roof shaded with a photovoltaic panel. These thermocouples were placed at the same level with respect to the thickness of the roof, and were spaced so that the surrounding thermal profile around each thermocouple would be approximately one dimensional. Figure 7 shows a schematic of this setup, with the placement of roof and interior ceiling thermocouples.

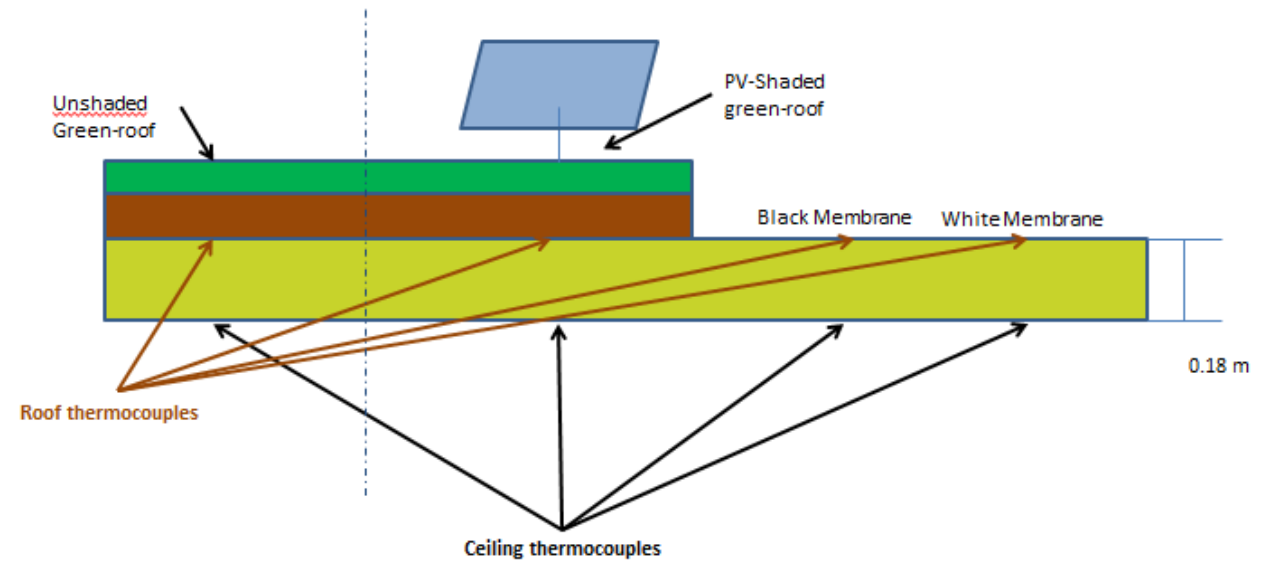

Figure 7: Side schematic showing placement of roof and ceiling thermocouples on the international harvester building

Infrared imagery revealed that the surface temperatures of the test patches are spatially uniform so that measured temperatures of each patch can be considered to be 
representative of what would be measured for an entire roof covered with that treatment (and thus validating the assumption that the heat transfer is mostly one-dimensional). Data for this field study were sampled at half-hourly intervals for a period of 2 years. The analysis presented in this manuscript, however, focuses on data from a single week in winter and summer: January 5-11, 2011 and July 5-11, 2012.

\subsection{1) Heat Transfer Model}

The use of heat flux sensors with coarse resolution was determined to be problematic due to the relatively small heat fluxes typically encountered in conduction through well-insulated roofs. As an alternative, the transient surface temperature was monitored on both the roof membrane surface and ceiling surface. For the purposes of this study the modeled roof construction was simplified to consist solely of an insulating layer of a representative thickness and conductivity. The surface temperature measurements were then used as boundary conditions for analysis using the onedimensional transient heat conduction equation with constant properties:

$$
\frac{\partial T}{\partial t}=\frac{k}{\rho C} \frac{\partial^{2} T}{\partial x^{2}}
$$

Use of a one-dimensional model might be questionable if the intent was to estimate actual heat fluxes through the test roof. Specifically, for a one-dimensional model to be valid requires that the transverse heat flux (parallel to the roof surface) be small compared with the heat flux perpendicular to the surface. The roof insulation has a reported thermal resistance of $5.3 \mathrm{~K}-\mathrm{m}^{2}-\mathrm{W}^{-1}$ (R-30 in IP units). The thickness $(\delta)$ of the roof insulation layer is $0.18 \mathrm{~m}$ and the smallest test patch had a side length $(\mathrm{L})$ of $0.75 \mathrm{~m}$. From scaling analysis one would expect that transverse conduction can be neglected 
when $\delta^{2} / \mathrm{L}^{2}<<1.0$. Since the value of this ratio is 0.06 in this study, one might expect the error in assuming one-dimensional heat transfer to be small, but not negligible. In fact, a "worst-case" idealized two-dimensional computational model of a $0.75 \mathrm{~m}$ wide patch of black roof (fixed at a surface temperature of $60^{\circ} \mathrm{C}$ ) sandwiched between patches of white roof (fixed at surface temperatures of $35^{\circ} \mathrm{C}$ ) indicated that neglecting transverse heat transfer might result in a maximum error of $7 \%$ in predicted fluxes into the building. Nevertheless, since the goal was to model the heat transfer into a hypothetical building comprised entirely of one type of roofing (white, black, green), transverse heat transfer can be neglected. The one-dimensional model is therefore appropriate provided the estimates of the bounding temperatures are reasonably accurate. This condition is met since the surface temperature across each patch of membrane material was observed to be relatively constant.

An explicit finite difference computer code was used to model the onedimensional heat conduction equation. This code was run for each test surface for one week in winter and one week in summer. Each simulation was initialized with a steady state (linear) temperature profile, used a spin-up time of 24 hours, had a time step of 1 second and used a grid spacing of $0.0045 \mathrm{~m}$ (satisfying stability requirements). The temperature profile within the roof was determined using the forward-time, central space finite difference approach using the data collected from the thermocouples on the roof surface and interior ceiling as boundary conditions.. Heat flux was determined as a function of time using a backwards, spatial finite difference approximation at the ceiling node for each time step. 


\section{2) Building Simulation}

To gain a more accurate picture of how the thermal loads from the roof impact overall building energy use, a simulation was performed using eQUEST, which is a program used for whole building energy modeling.

eQUEST is a simulation tool used for building energy modeling. It has features including geometry modeling, internal load analysis, building envelope property selection, daylighting, solar gain calculation, infiltration and ventilation, as well as complete HVAC equipment analytics. Although use of other building simulation tools such as EnergyPlus and TRACE is growing, the quick simulation times associated with eQUEST made it particularly attractive for the numerical analysis performed in this work.

eQUEST uses a fraction multiplier to calculate the distribution of direct solar and diffuse radiation on exterior and interior surfaces[32], and a simplified heat balance algorithm for calculating space and system loads. EnergyPlus is considered to be more accurate in calculating envelope gains, but the priority for this analysis was comparing the difference in cumulative energy savings between a building with a black roof and white roof, which supported using eQUEST for performing the building simulation.

The numerical simulation was based around a parametric analysis which was focused on the difference between two identical buildings, one with a black roof surface and the other with a white roof surface. Thermal loads into the roof are dependent on three major parameters:

1. Roof Area

2. Thermal properties of roofing material

3. Surface Albedo 
For the analysis, each trial involved some permutation of the first two variables by keeping all variables except for the surface albedo the same, and doing two runs per trial, with one run using a conventional low albedo roof and the other using a built up white roof. For simplification, a stock mid-rise building was selected, four stories in height, with multiple trials conducted for roof area varying from $5000 \mathrm{ft}^{2}$ to $25000 \mathrm{ft}^{2}$, and for a varying roof insulation from R-7 to R-35 (IP units). Also, an identical schedule of trials was performed in the Phoenix climate. Typical meteorological year (TMY) data was loaded into a weather file to model the Portland and Phoenix climates.

Default conditions were selected in eQUEST for all other parameters, including the sizing of the chiller and the schedule of the fans. Default conditions for HVAC include autosizing based on floor area, and for the mid-rise office selection, the default option for cooling is a chilled water system. This selection of default conditions worked within the framework of this analysis, because the parameter being considered for each run is the difference in thermal load or energy consumption between identical buildings where one roof is black and the other roof is white. This method isolates the impact of the surface albedo upon the overall building energy use. Thermal loads are independent of the HVAC system, therefore the only parameters of priority in the analysis were roof area and roof insulation.

In the analysis, the annual cooling load, annual heating load and monthly cooling load for July were collected for each area and insulation combination. Insulation was fixed at increments of 7 units from R-7 to R-35, assuming an insulation layer of polyisocyanurate. From each run of the simulation, the heating and cooling loads into the 
roof were recorded, as were the space cooling and space heating energy requirements calculated for the simulation parameters. Then, these values from the white roof simulation were subtracted from the black roof for each pair of runs, and the difference in heating load, cooling load, space cooling and space heating energy requirements were analyzed against the input parameters for the building simulation. The results of this simulation are presented in the following chapter. 


\section{Chapter 3: Results}

\section{1) Field Experiment}

The results from the field experiment are shown in Figures 8-11. The summer-time temperature data on the boundaries of the roof is shown in Figure 8. One notable finding is that the peak difference in temperature between the black and white surface is 30 degrees $\mathrm{C}$, which is in good agreement with findings from previous literature.

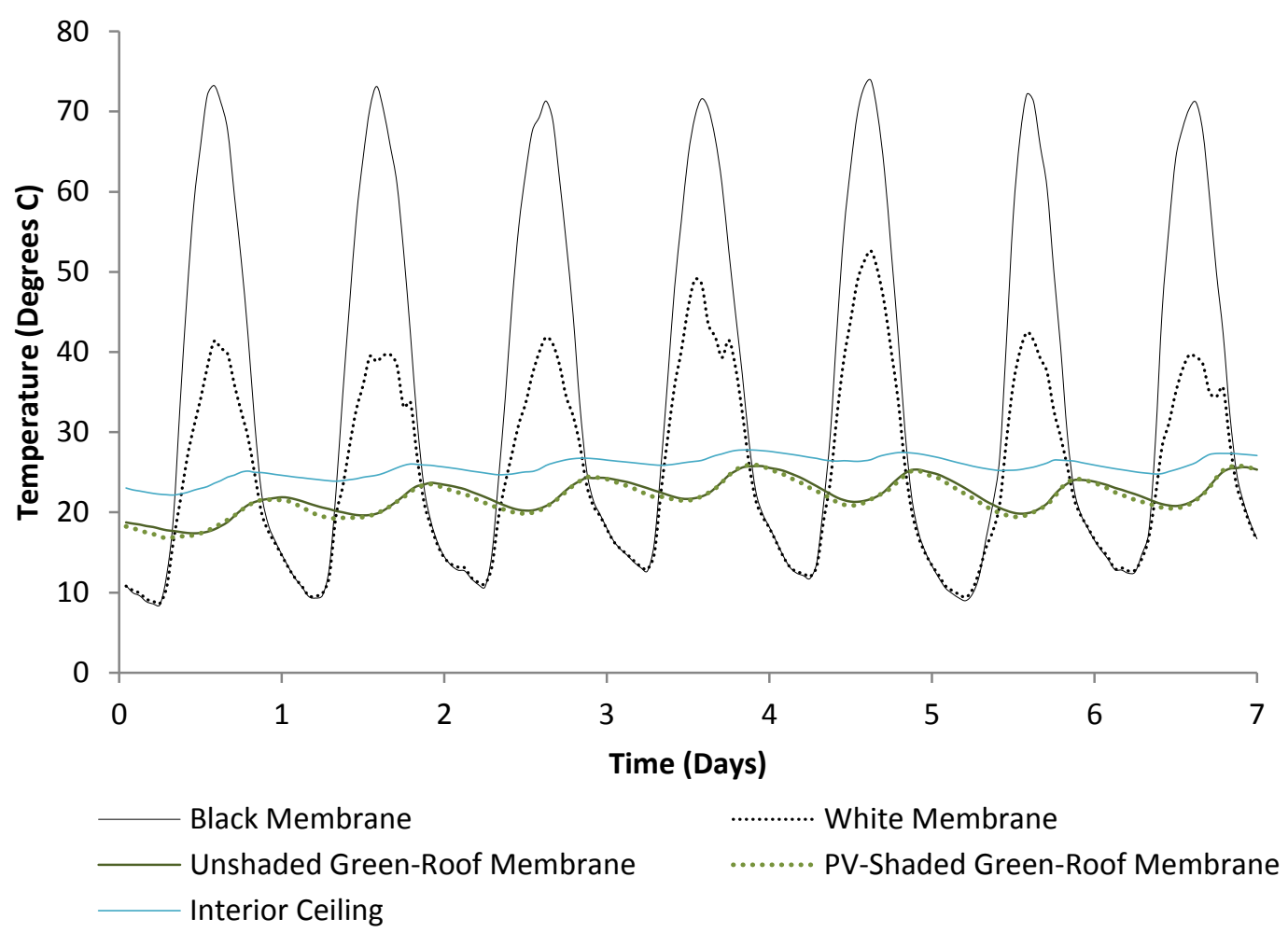

Figure 8: Temperature boundary data taken from July 5, 2012 to July 11, 2012 on the International Harvester roof

The temperature boundary data were used to calculate estimates of heat flux, and are presented as a difference between the black and white heat flux profiles for the summer week of July 5-11, 2012 in Figure 9. Notable findings are the average peak difference of 
30 degrees $\mathrm{C}$ between the black and white roofs. Both the dark and white roof temperature profiles oscillate around the ceiling temperature.

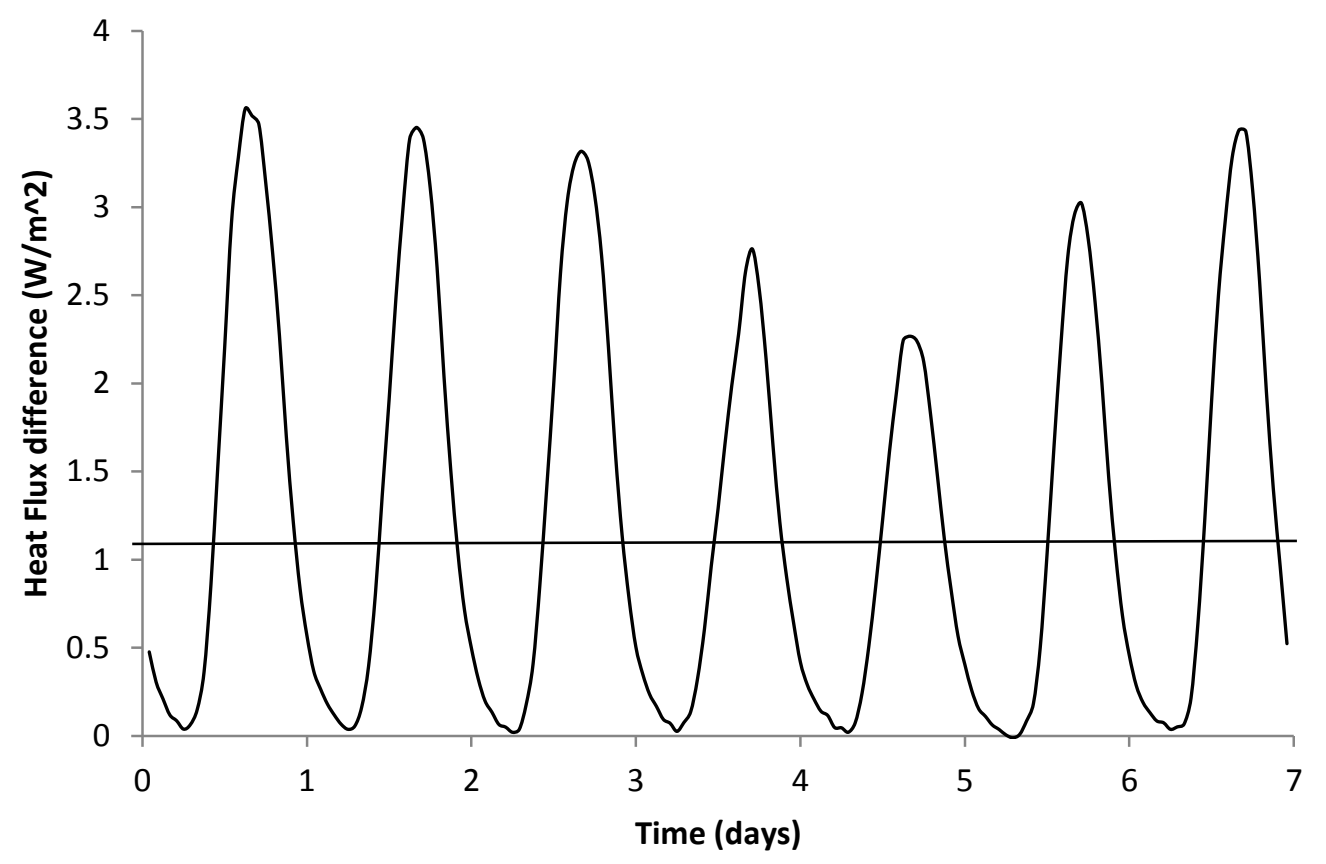

Figure 9: Difference in heat flux between the dark roof and white roof surfaces taken over summer period of July 5-11, 2012

The heat flux profile in Figure 9 shows that the maximum difference in heat flux between the dark and white roof appears to occur consistently around 5:00 or 6:00 pm. The horizontal line refers to the average value of heat flux savings $\left(1.24 \mathrm{~W} / \mathrm{m}^{2}\right)$ over the entire summer week. This indicates an extrapolated reduction in the cooling load flux for the International Harvester Building of $0.92 \mathrm{kWh} / \mathrm{m}^{2}$ in the month of July. 


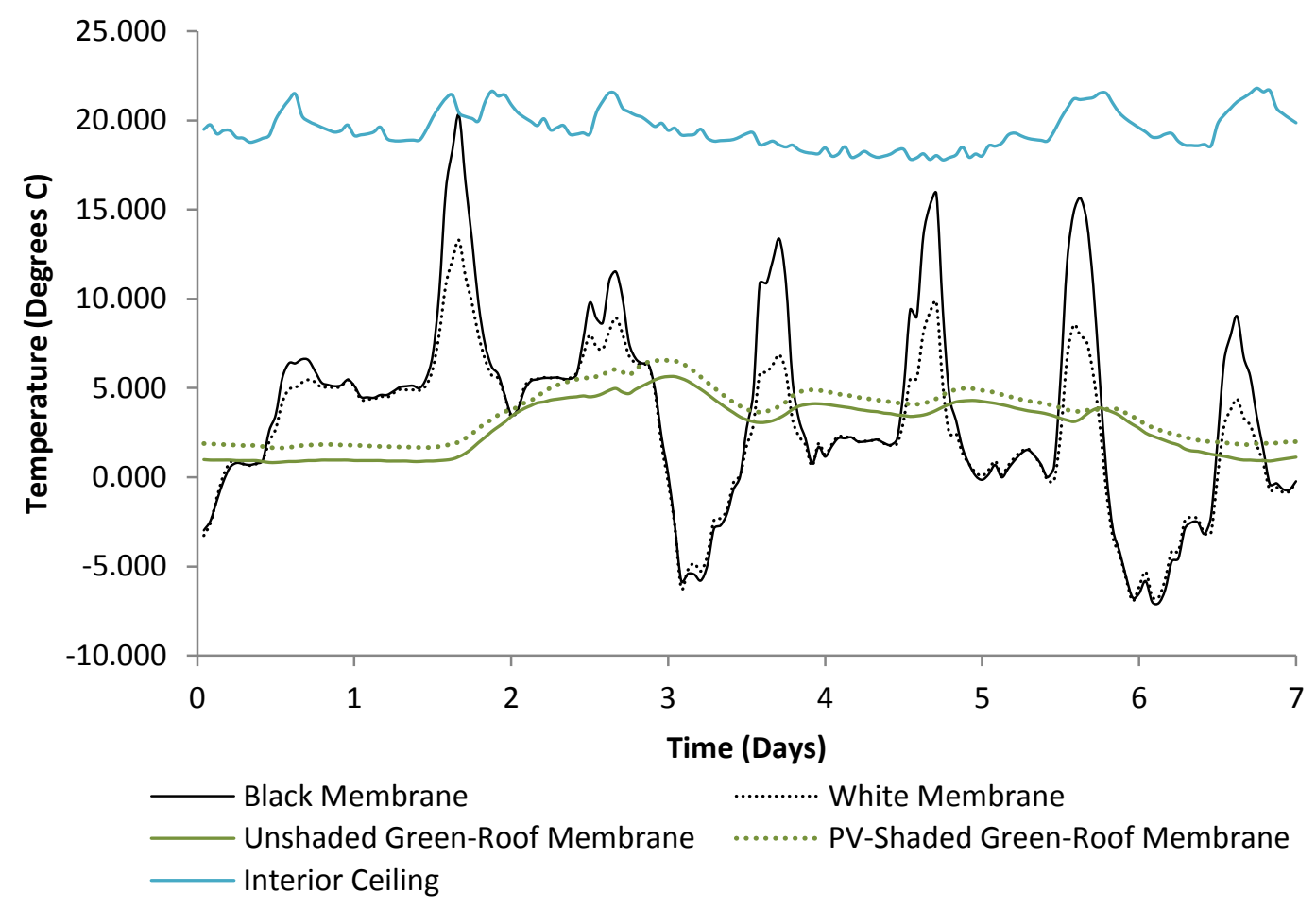

Figure 10: Temperature boundary data taken from International Harvester during winter (January 5, 2011-January 11, 2011)

The temperature boundary profile in Figure 10 reveals that the roof surface temperatures were consistently less than the interior ceiling temperature for all of the surfaces. The corresponding heat flux is consistently out of the roof for all of the roof surfaces, indicating that for the winter period, the building loses heat through the roof regardless of the roof system used. 


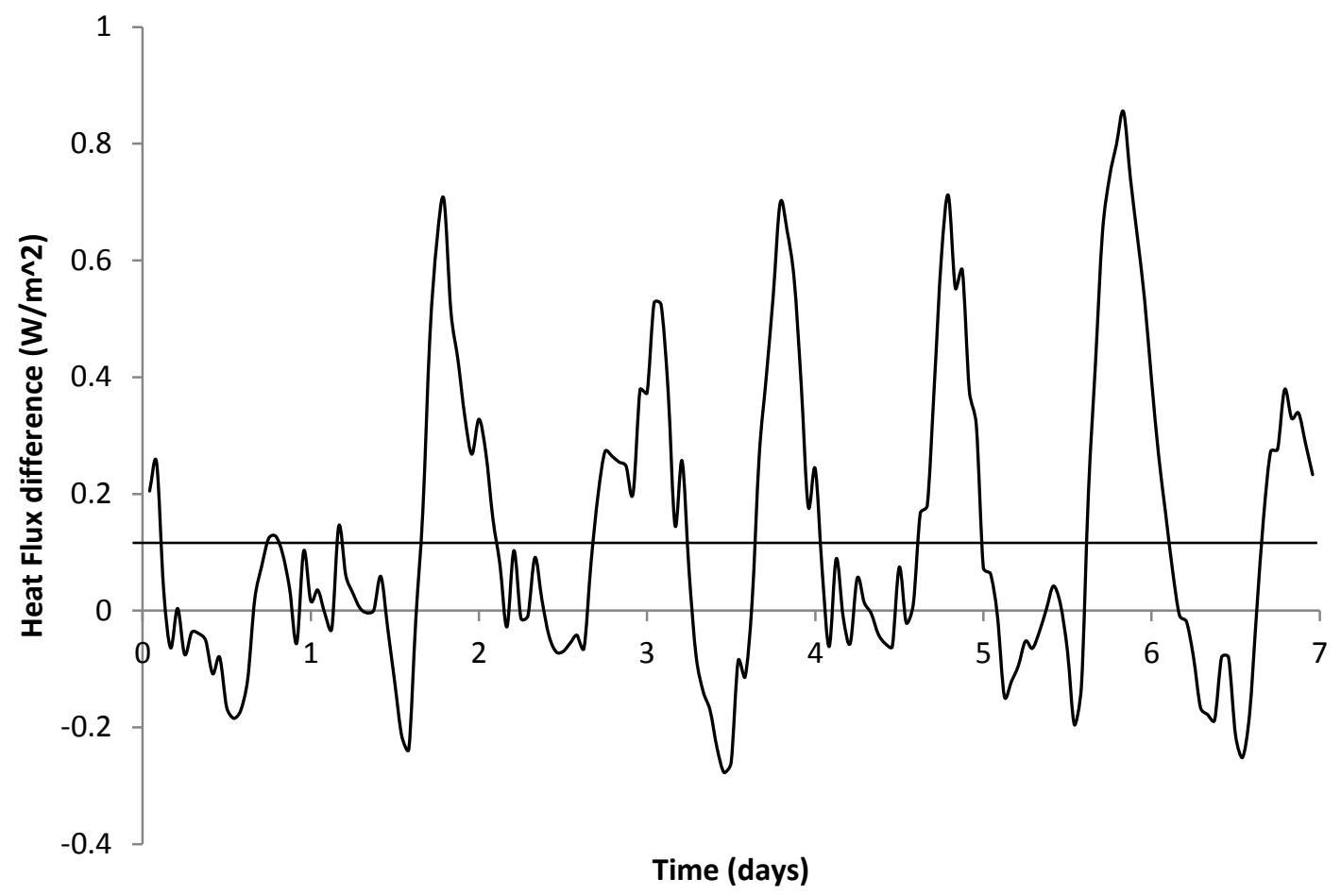

Figure 11: Difference in heat flux between the dark roof and white roof surfaces taken over winter period of June 5-11, 2011.

Figure 11 shows the difference in heat flux through the roof between the dark and white roof surface for the winter period. The horizontal line corresponds to the average difference in heat flux into the roof between the dark and white roof surfaces, and indicates that relative to the white roof, the dark roof reduces heat loss from the building by $0.12 \mathrm{~W} / \mathrm{m}^{2}$ on average for the entire week. This can be extrapolated to a heat loss reduction of $0.09 \mathrm{kWh} / \mathrm{m}^{2}$ for the month of January. 


\section{2) Building Simulation}

The results of the building simulation run in eQUEST are displayed in the following figures and tables. Figure 12 shows a plot for cooling energy savings in July vs roof area at fixed values of insulation, with the energy savings presented as the difference in July electricity consumption between the dark and white roof modeled in Portland, OR.

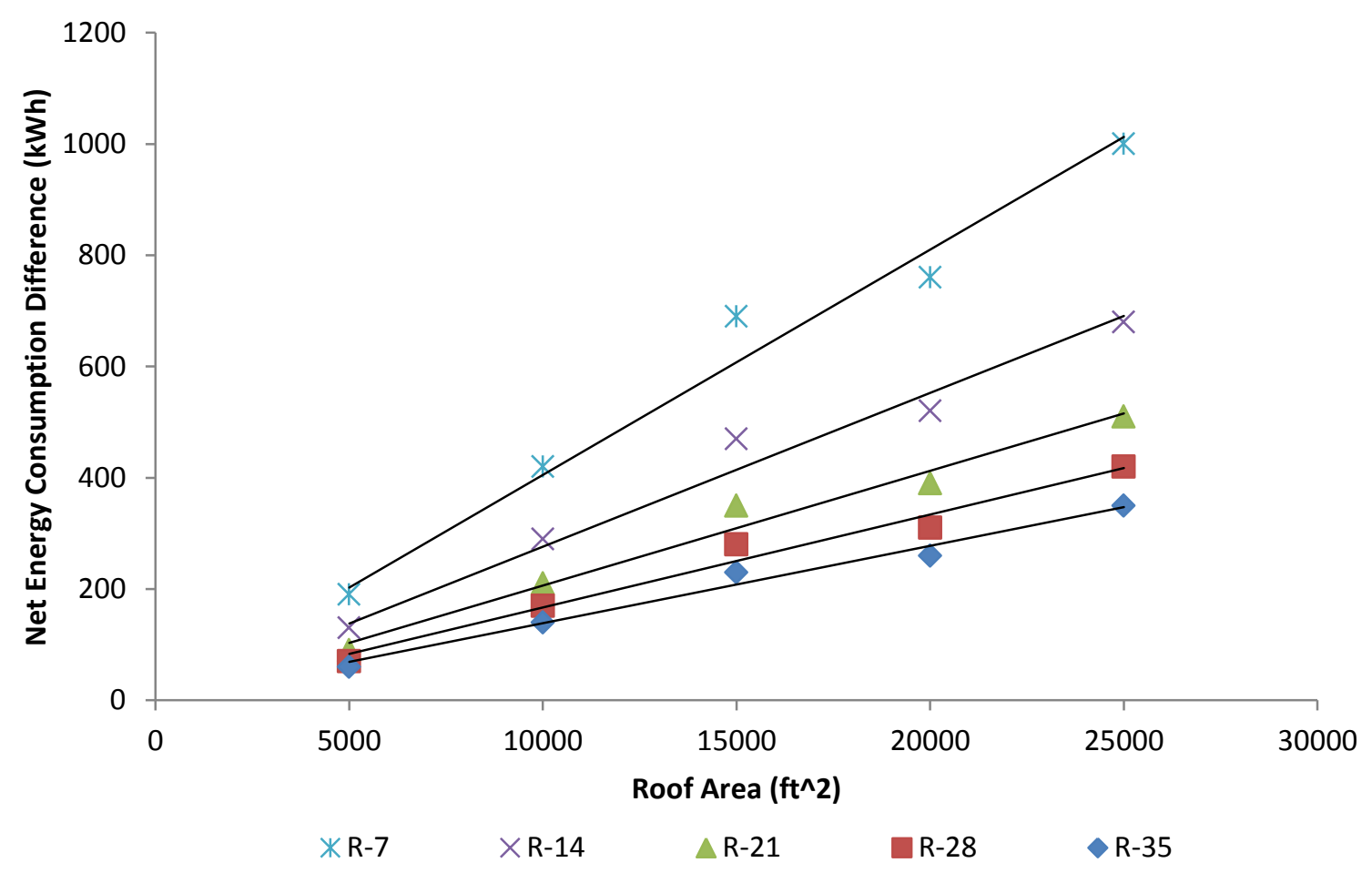

Figure 12: Difference in electricity consumed in July for cooling (dark roof simulation vs white roof simulation) plotted vs roof area. Simulation runs performed for roof insulation value of R-7, R-14, R21, R-28 and R-35.

The slopes of the trend-lines shown in the graph are as follows (R-values in Figure 13 and in all following figures are provided in English units):

R-7: $0.0405 \mathrm{kWh} / \mathrm{ft}^{2}$

R-14: $0.0276 \mathrm{kWh} / \mathrm{ft}^{2}$

R-21: $0.0206 \mathrm{kWh} / \mathrm{ft}^{2}$

R-28: $0.0167 \mathrm{kWh} / \mathrm{ft}^{2}$

R-35: $0.0139 \mathrm{kWh} / \mathrm{ft}^{2}$ 
Figure 13 shows a plot of annual cooling energy savings vs roof area at fixed values of insulation, with the energy savings presented as the difference in annual electricity consumption between the dark roof and the white roof modeled in Portland, OR.

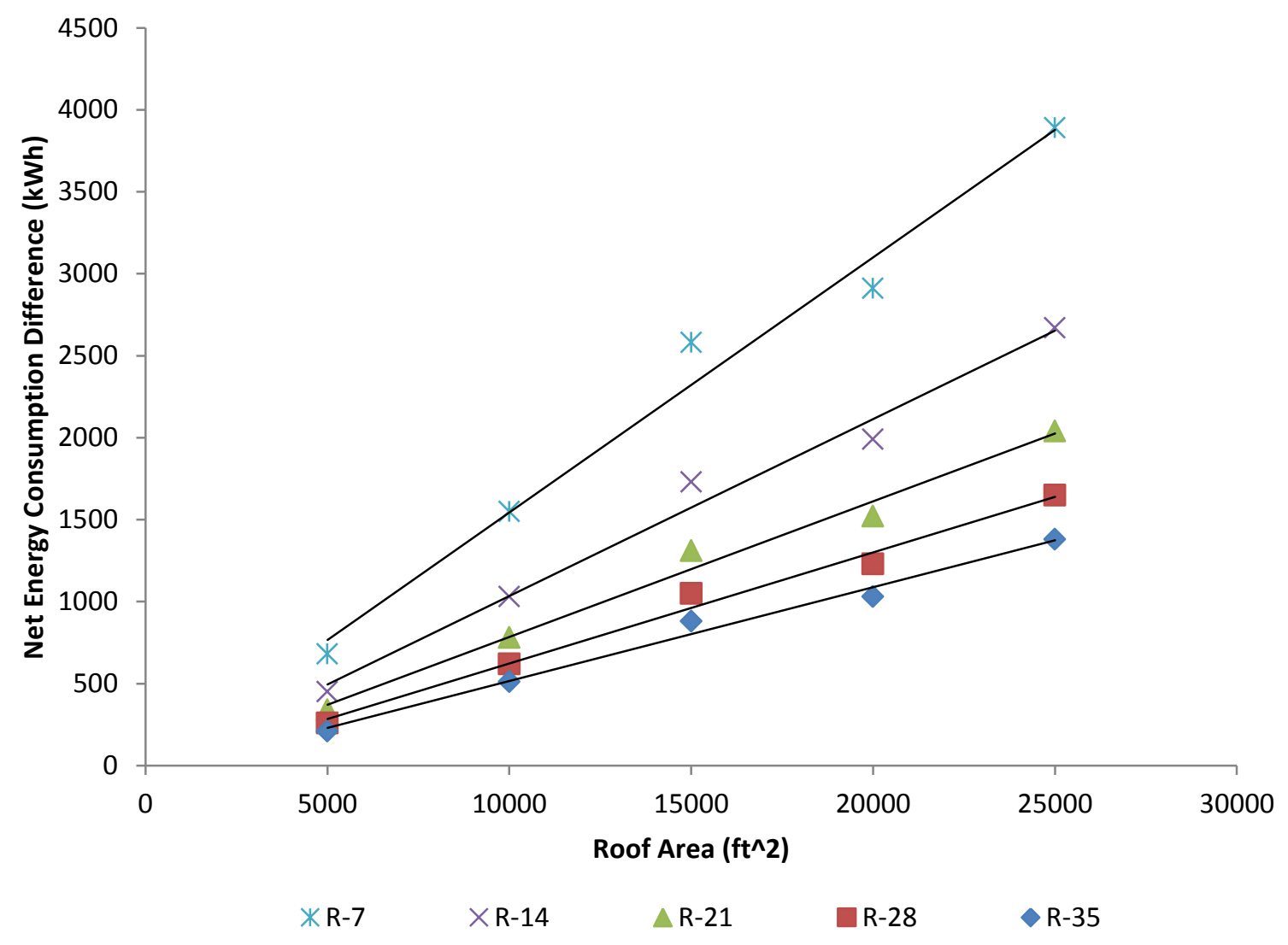

Figure 13: Difference in electricity consumed annually for cooling (dark roof simulation vs white roof simulation) plotted vs roof area. Simulation runs performed for roof insulation value of R-7, R-14, R21, R-28 and R-35.

The slopes of the trend-lines shown in the graph are as follows:

R-7: $\quad 0.1556 \mathrm{kWh} / \mathrm{ft}^{2}$

R-14: $0.1080 \mathrm{kWh} / \mathrm{ft}^{2}$

R-21: $0.0828 \mathrm{kWh} / \mathrm{ft}^{2}$

R-28: $0.0572 \mathrm{kWh} / \mathrm{ft}^{2}$

R-35: $0.0678 \mathrm{kWh} / \mathrm{ft}^{2}$ 
Figure 14 shows a plot of annual heating energy difference vs roof area at fixed values of insulation, presented as the difference in natural gas consumption between the dark and white roof modeled in Portland.

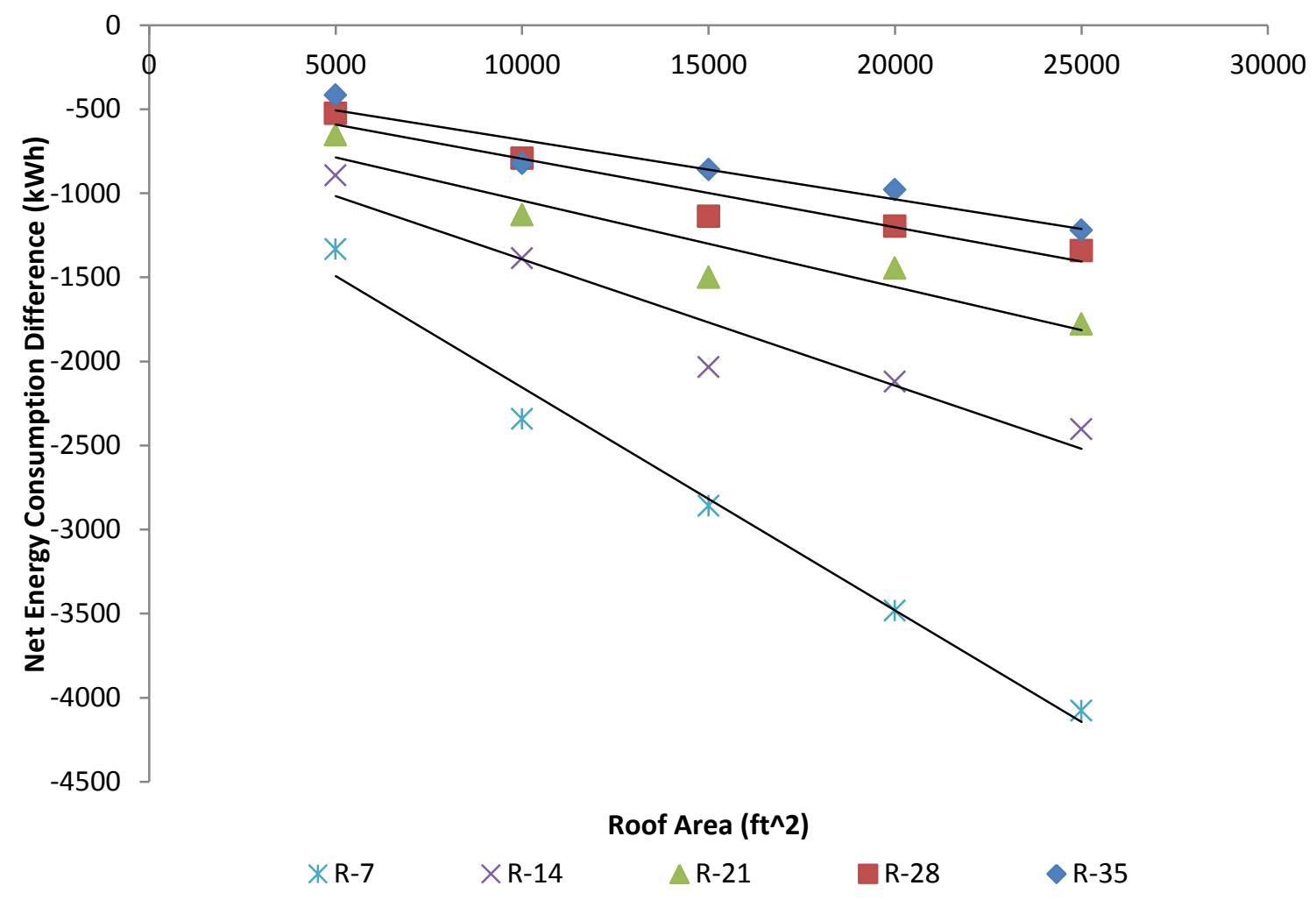

Figure 14: Difference in natural gas consumed annually for heating (dark roof simulation vs white roof simulation) plotted vs roof area. Simulation runs performed for roof insulation value of $R-7$, $R$ 14, R-21, R-28 and R-35. Building simulation performed in Portland, OR.

The slopes of the trend-lines shown in the graph are as follows:

$\mathrm{R}-7: \quad-0.1325 \mathrm{kWh} / \mathrm{ft}^{2}$

R-14: $\quad-0.0751 \mathrm{kWh} / \mathrm{ft}^{2}$

$\mathrm{R}-21:-0.0514 \mathrm{kWh} / \mathrm{ft}^{2}$

R-28: $-0.0408 \mathrm{kWh} / \mathrm{ft}^{2}$

R-35: $-0.0352 \mathrm{kWh} / \mathrm{ft}^{2}$ 
Figure 15 plots the slopes obtained from the linear regression of cooling energy use in the month of July vs area (from Figure 12) against the R-value of the insulating roof layer. Slopes recorded from Figure 12 are reported in SI units in Figure 15. The simulation results from eQUEST imply that this relationship of energy flux used vs R-value is an inverse relationship.

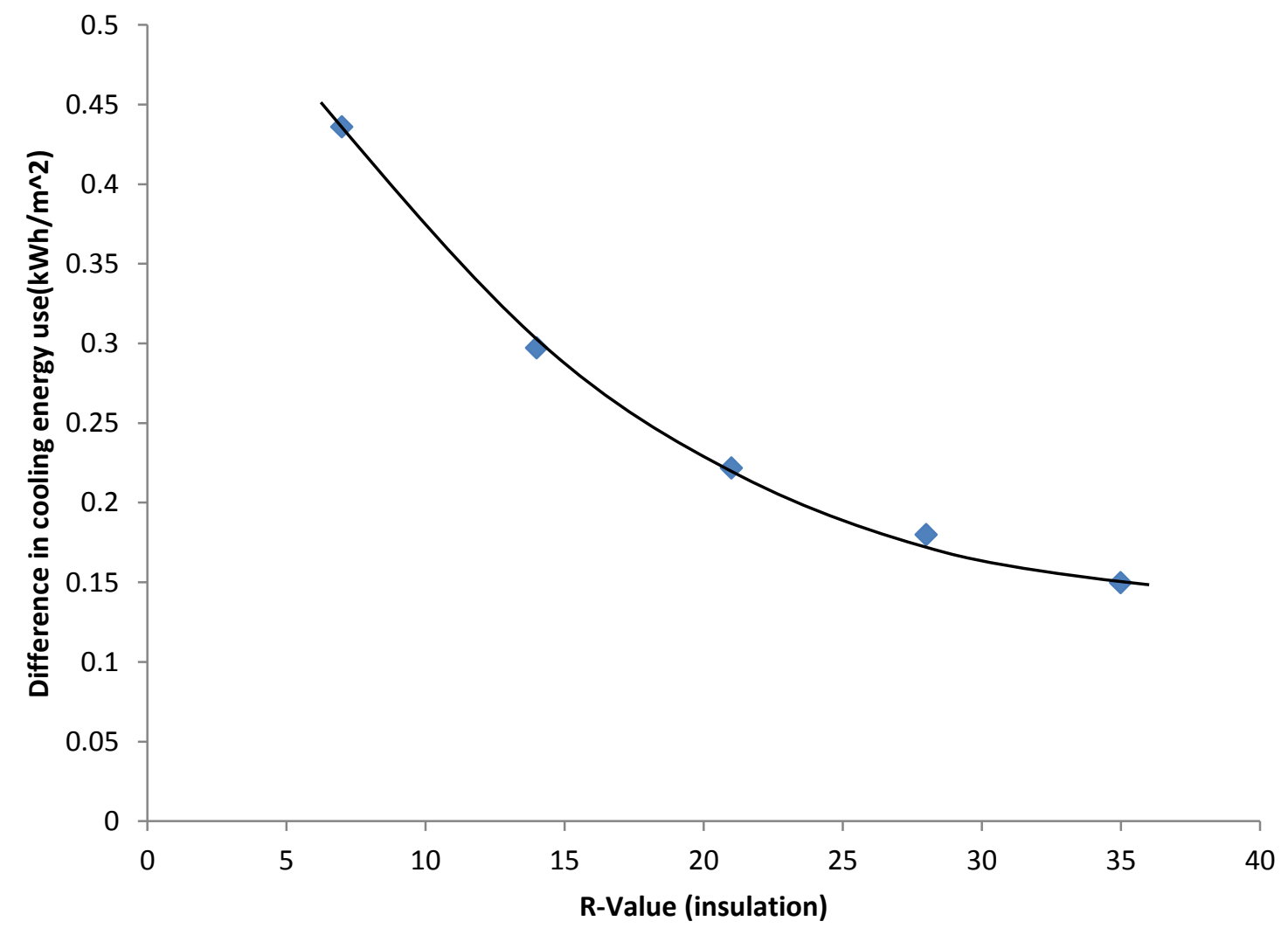

Figure 15: Difference in electricity consumed for cooling per unit area in the month of July (dark roof simulation vs white roof simulation) plotted vs R-value (IP units). The vertical axis corresponds to the SI units of the slope of the energy consumption curves. Building simulation performed in Portland, OR. 
Figure 16 plots the slopes obtained from the linear regression of annual cooling energy use vs area (from Figure 13) against the R-value of the insulating roof layer. Slopes recorded from Figure 13 are reported in SI units in Figure 16. For less insulated buildings, the ratio between the annual flux and the total flux for July is approximately 4:1, this ratio decreases marginally when considering more well-insulated buildings, decreasing to a value of 3.5:1 when looking at a very well insulated roof.

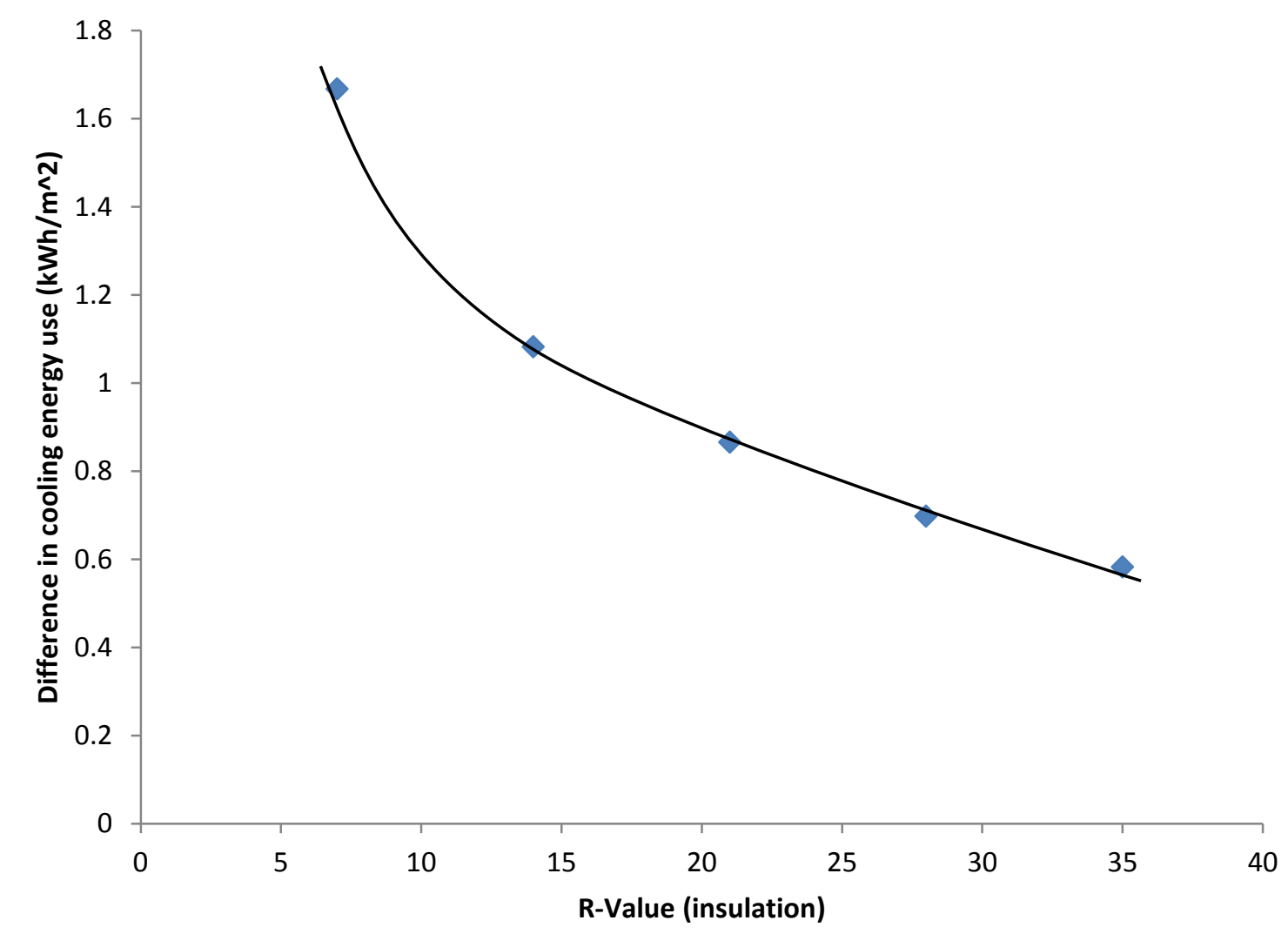

Figure 16: Difference in electricity consumed annually for cooling per unit area (dark roof simulation vs white roof simulation) plotted vs R-value (IP units). Building simulation performed in Portland, OR. 
Figure 17 plots the slopes obtained from the linear regression of annual heating energy use vs area (from Figure 14) against the R-value of the insulating roof layer. Slopes recorded from Figure 14 are reported in SI units in Figure 17. For a specific value of insulation, the cooling energy savings flux slightly outweighs the heating energy penalty flux from replacing the dark roof with a white roof, calculated by taking the difference in magnitude between the savings associated with annual electricity use and the increased amount of natural gas consumed (Figure 16 and Figure 17) at a specific insulation value.

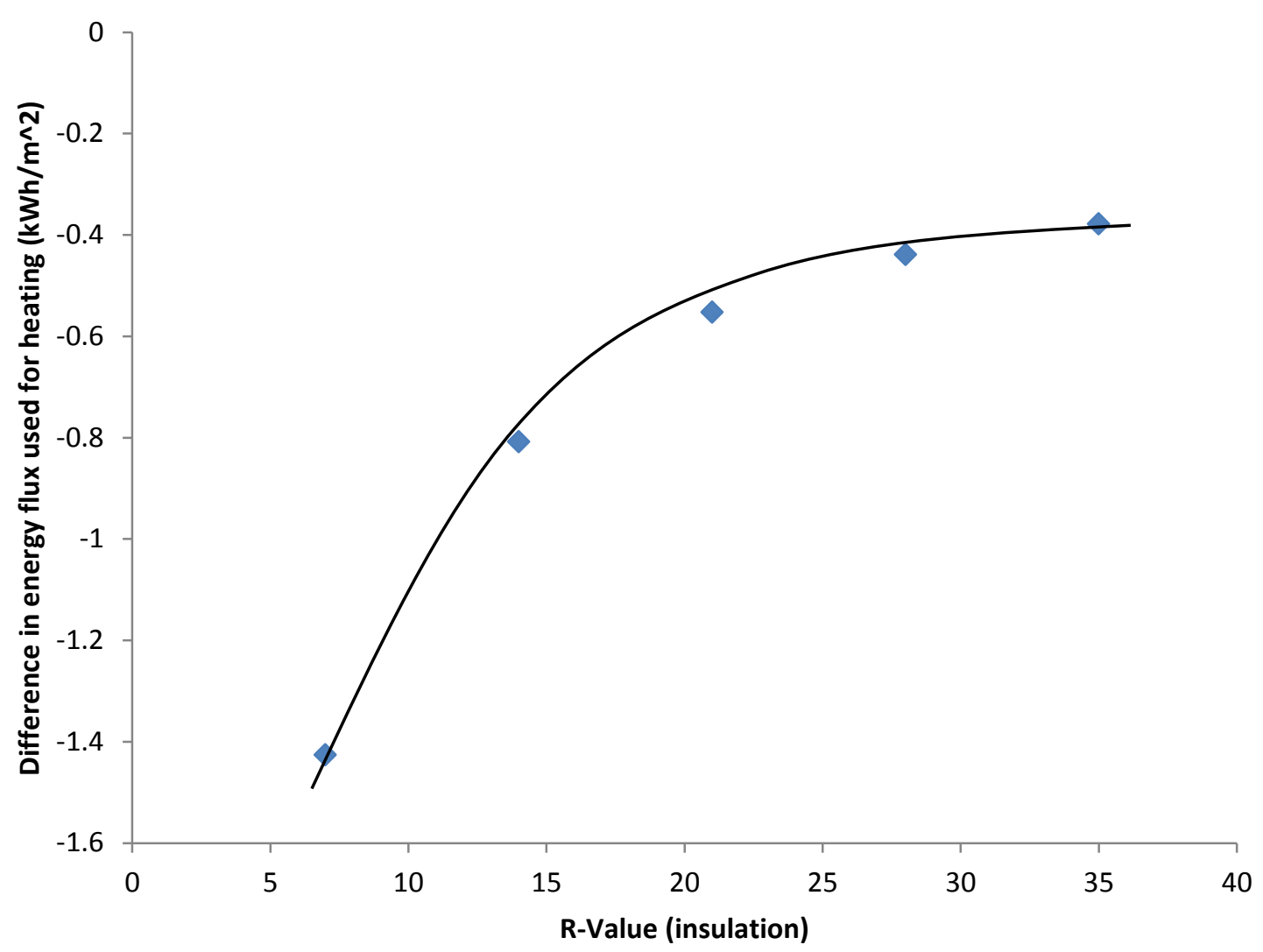

Figure 17 Difference in natural gas consumed annually for heating per unit area (dark roof simulation vs white roof simulation) plotted vs R-value (IP units). Building simulation performed in Portland, OR. 
Figure 18 plots the reduction in rooftop cooling load per unit area in the month of July as a function of the R-Value of the insulating material. This cooling load reduction flux is obtained from eQUEST by obtaining the linear regression of the cooling load reduction plotted against the roof area. Cooling load reduction is a minimum at R-35 of approximately $0.58 \mathrm{kWh} / \mathrm{m}^{2}$. From Figure 15, the cooling load energy savings at R-35 is $0.15 \mathrm{kWh} / \mathrm{m}^{2}$, a ratio of almost $4: 1$

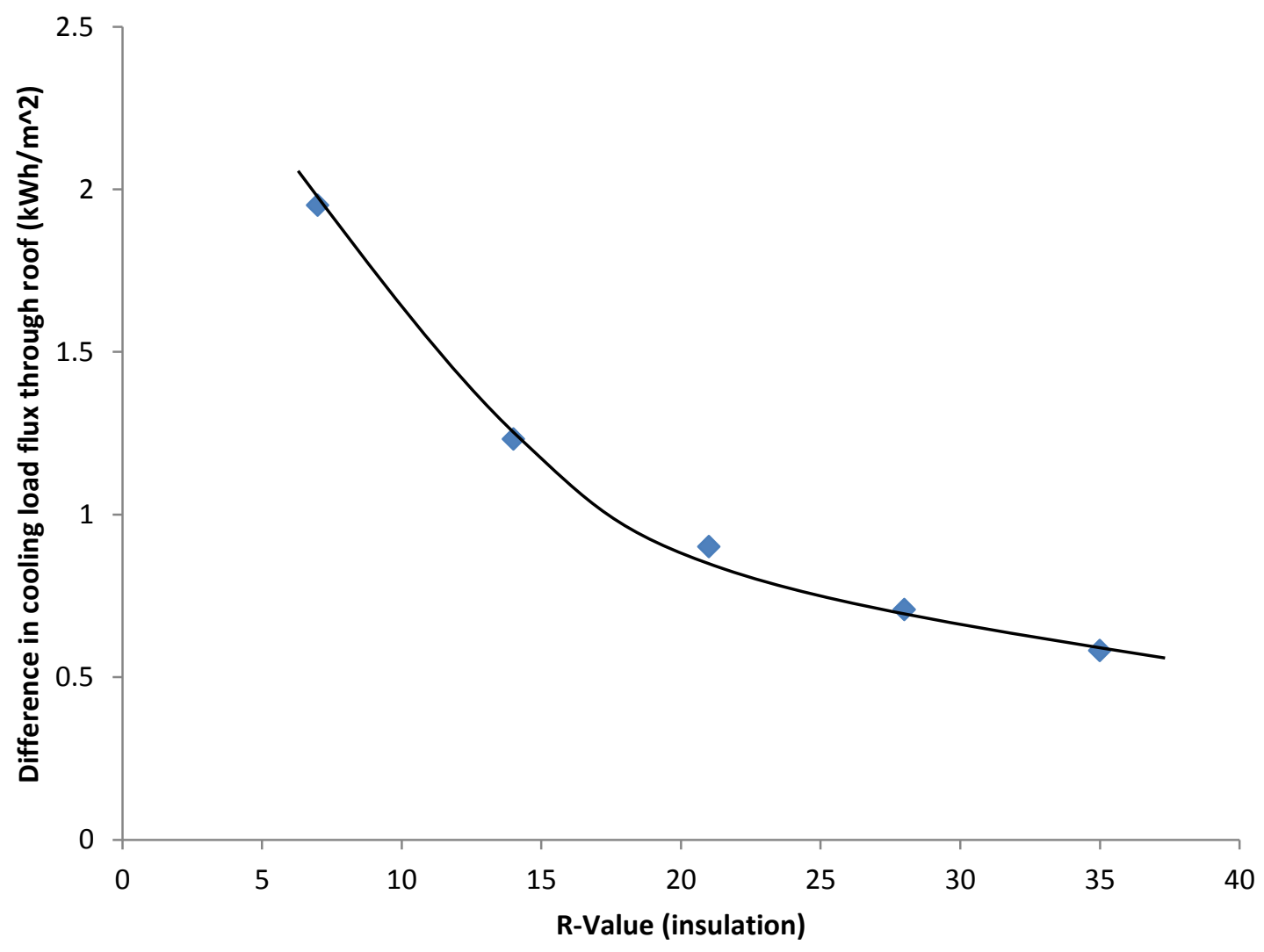

Figure 18: Difference in roof-top cooling load contribution per unit area for July (dark roof simulation vs white roof simulation) plotted vs R-value (IP units). Building simulation performed in Portland, OR. 
Figure 19 plots the reduction in annual rooftop cooling load per unit area as a function of the R-Value of the insulating material. This cooling load reduction flux is obtained from eQUEST by obtaining the linear regression of the cooling load reduction plotted agaisnt the roof area. Cooling load reduction is a minimum at R-35 of approximately 2.66 $\mathrm{kWh} / \mathrm{m}^{2}$. From Figure 16, the cooling load energy savings at R-35 is $0.58 \mathrm{kWh} / \mathrm{m}^{2}$, a ratio of about 5:1.

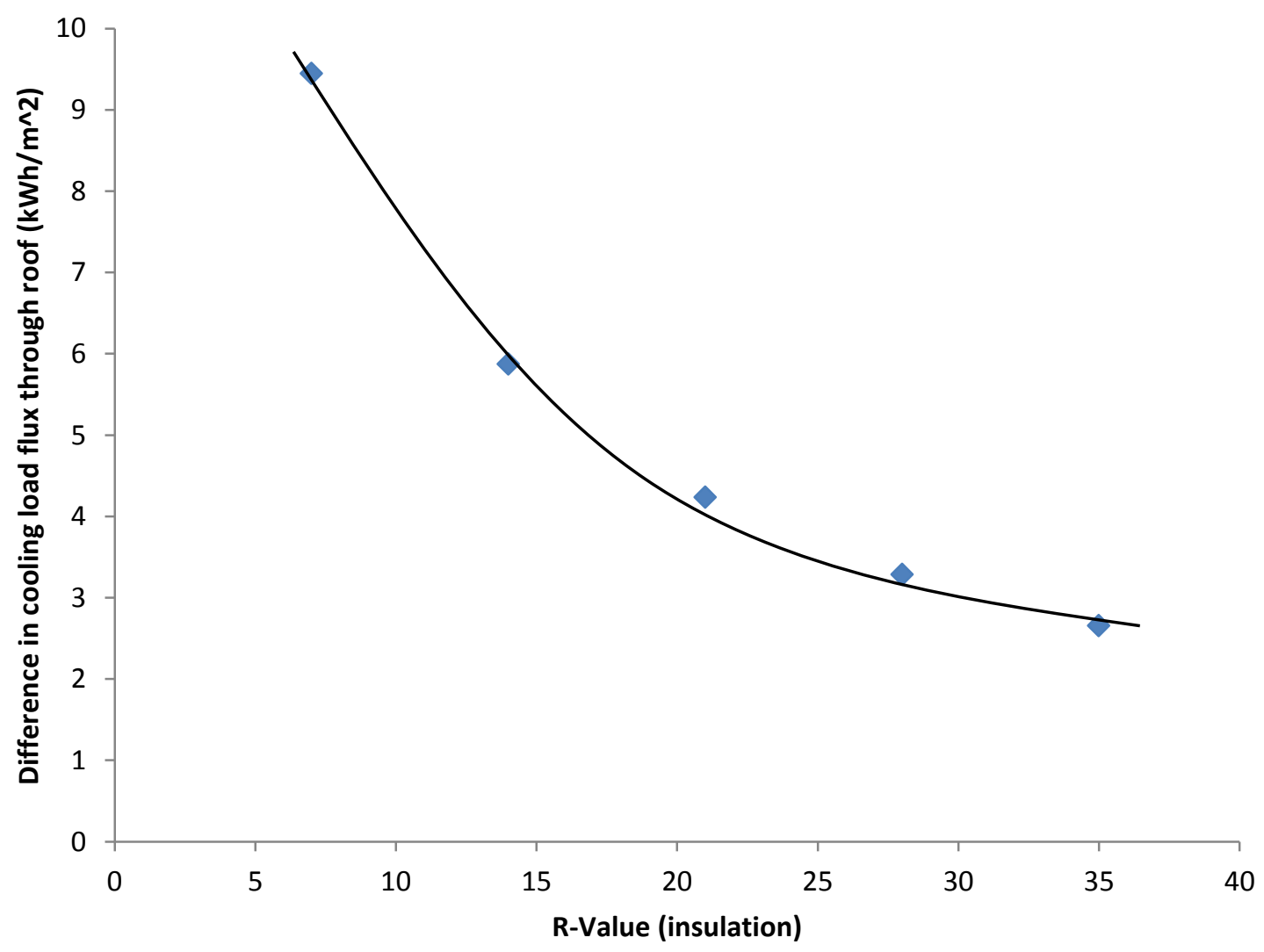

Figure 19: Difference in annual roof-top cooling load contribution per unit area (dark roof simulation vs white roof simulation) plotted vs R-value (IP units). Building simulation performed in Portland, OR. 
Figure 20 plots the reduction in annual rooftop heating load per unit area as a function of the R-Value of the insulating material. This heating load reduction flux is obtained from eQUEST by obtaining the linear regression of the cooling load reduction plotted agaisnt the roof area. Cooling load reduction is a minimum (in magnitude) at R-35 of approximately $-1.31 \mathrm{kWh} / \mathrm{m}^{2}$. The negative sign indicates that the rooftop heating load increases by going from a dark roof to a white roof. From Figure 17, the space heating energy savings at R-35 is $-0.38 \mathrm{kWh} / \mathrm{m}^{2}$, a ratio of about $4: 1$.

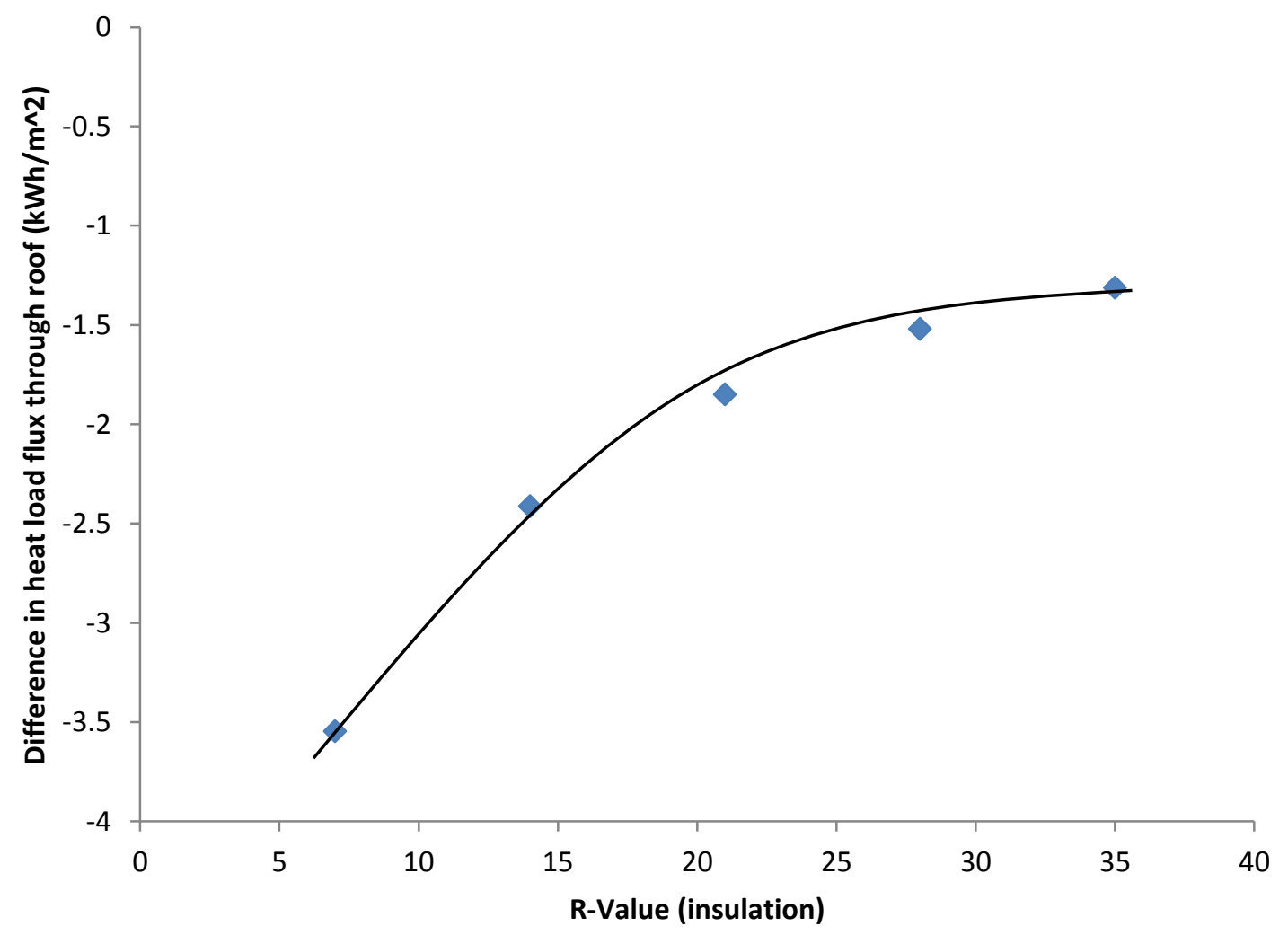

Figure 20: Difference in annual roof-top heating load contribution per unit area (dark roof simulation vs white roof simulation) plotted vs R-value (IP units). Building simulation performed in Portland, OR. 
Figure 21 shows a plot for cooling energy savings in July vs roof area at fixed values of insulation, with the energy savings presented as the difference in July electricity consumption between the dark and white roof modeled in Phoenix, AZ.

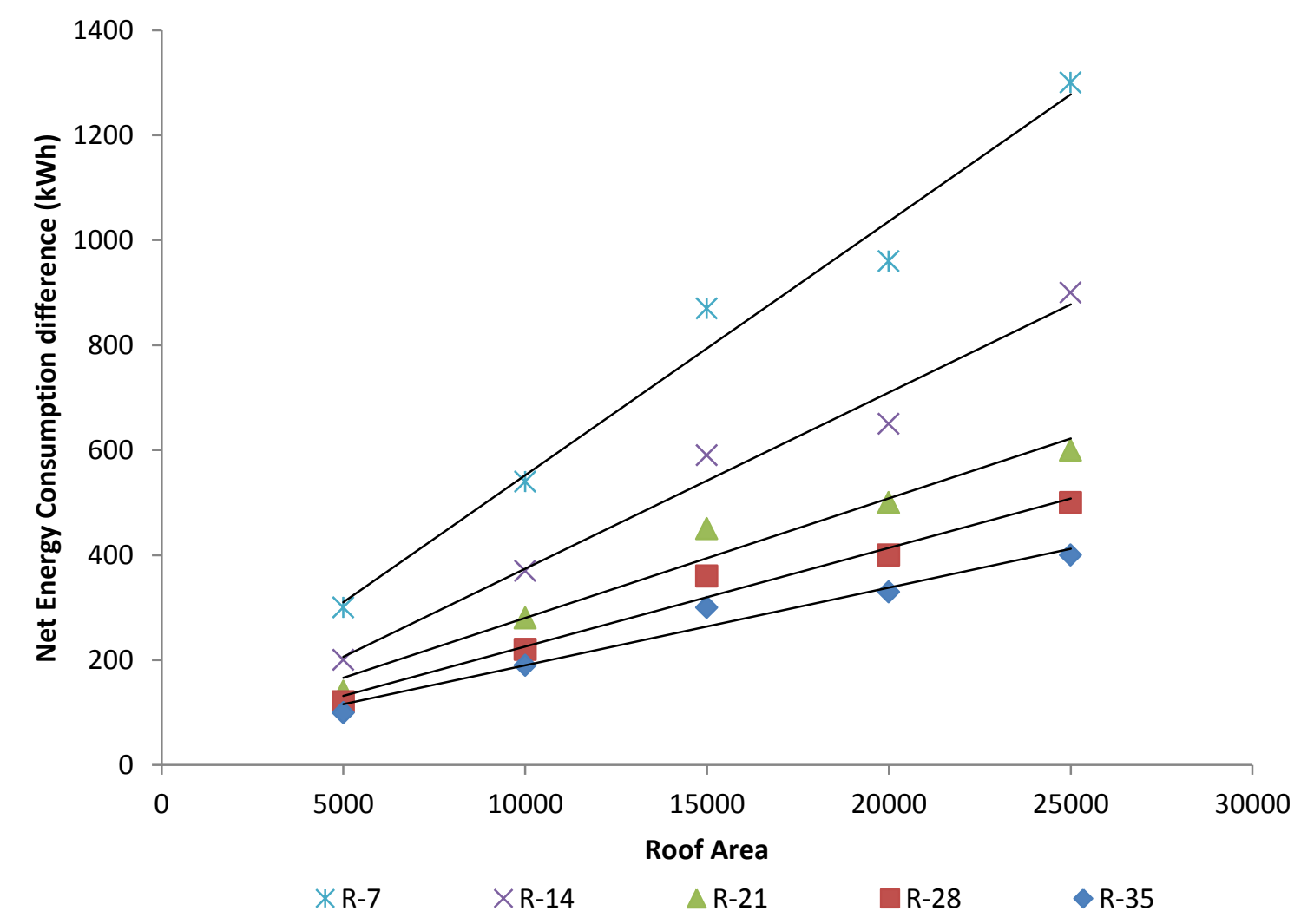

Figure 21: : Difference in electricity consumed in July for cooling (dark roof simulation vs white roof simulation) plotted vs roof area. Simulation runs performed for roof insulation value of R-7, R-14, R21, R-28 and R-35. Building Simulation performed in Phoenix, AZ.

The slopes of the trend-lines shown in the graph are as follows:

R-7: $0.0484 \mathrm{kWh} / \mathrm{ft}^{2}$

R-14: $0.0336 \mathrm{kWh} / \mathrm{ft}^{2}$

R-21: $0.0228 \mathrm{kWh} / \mathrm{ft}^{2}$

R-28: $0.0188 \mathrm{kWh} / \mathrm{ft}^{2}$

R-35: $0.0148 \mathrm{kWh} / \mathrm{ft}^{2}$ 
Figure 22 shows a plot of annual cooling energy savings vs roof area at fixed values of insulation, with the energy savings presented as the difference in annual electricity consumption between the dark roof and the white roof modeled in Phoenix.

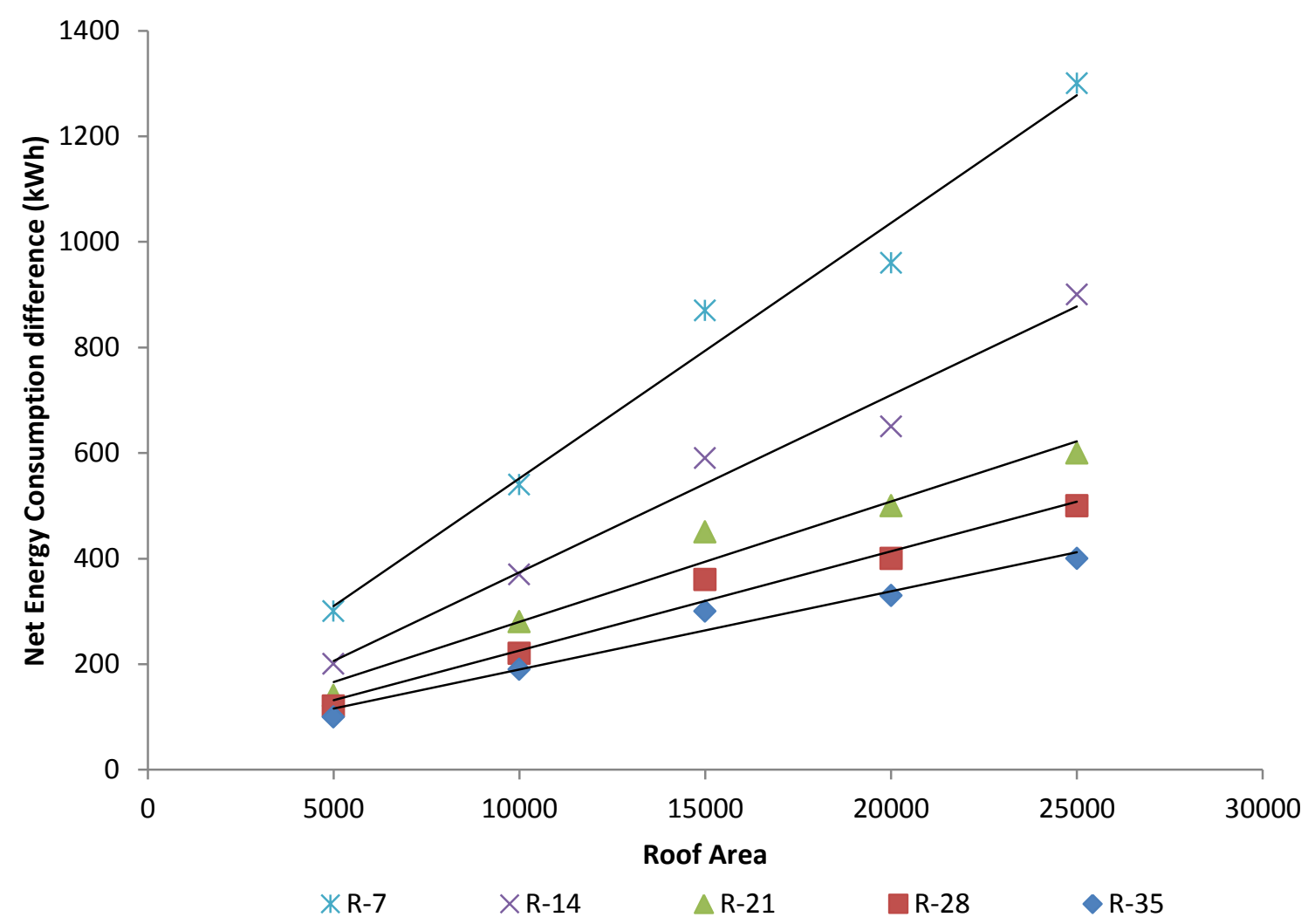

Figure 22: Difference in electricity consumed annually for cooling (dark roof simulation vs white roof simulation) plotted vs roof area. Simulation runs performed for roof insulation value of R-7, R-14, R21, R-28 and R-35. Building simulation performed in Phoenix, AZ.

The slopes of the trend-lines shown in the graph are as follows:

R-7: $\quad 0.1556 \mathrm{kWh} / \mathrm{ft}^{2}$

R-14: $0.1080 \mathrm{kWh} / \mathrm{ft}^{2}$

R-21: $0.0828 \mathrm{kWh} / \mathrm{ft}^{2}$

R-28: $0.0572 \mathrm{kWh} / \mathrm{ft}^{2}$

R-35: $0.0678 \mathrm{kWh} / \mathrm{ft}^{2}$ 
Figure 23 shows a plot of annual heating energy difference vs roof area at fixed values of insulation, prseented as the difference in natural gas consumption between the dark and white roof modeled in Phoenix. The plot for R-7 insulation is not shown in the graph as the features of the higher insulation curves disappear when overlaid on the same curve.

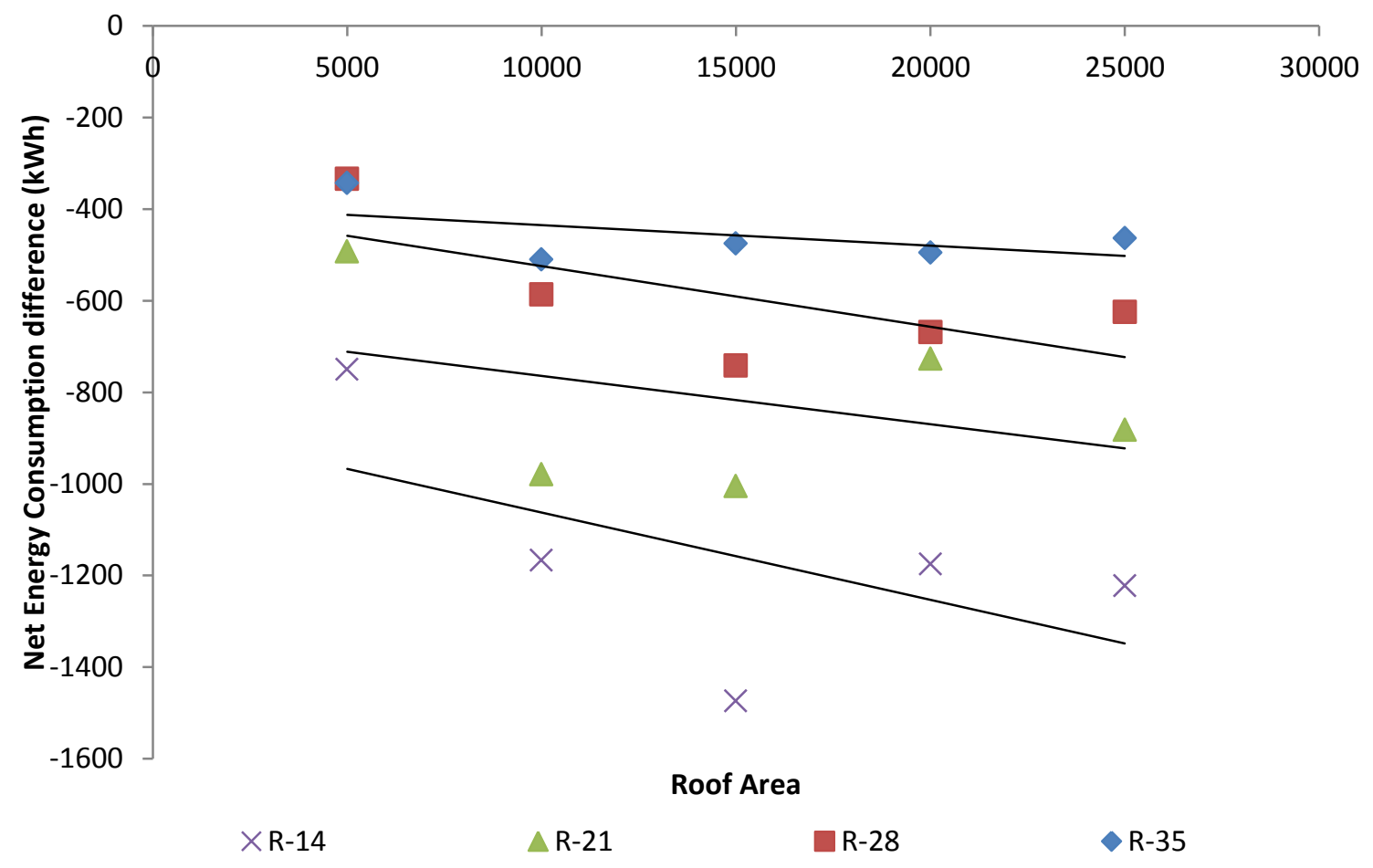

Figure 23: Net difference in annual heating energy use (dark roof simulation vs white roof simulation) plotted vs roof area. Simulation runs performed for roof insulation value of R-14, R-21, R-28 and R-35. Building simulation performed in Phoenix, AZ.

Slopes of trend-lines are provided below:

R-7: $\quad-0.0381 \mathrm{kWh} / \mathrm{ft}^{2}$

R-14: $-0.0191 \mathrm{kWh} / \mathrm{ft}^{2}$

$\mathrm{R}-21:-0.0106 \mathrm{kWh} / \mathrm{ft}^{2}$

R-28: $-0.0132 \mathrm{kWh} / \mathrm{ft}^{2}$

R-35: $-0.0045 \mathrm{kWh} / \mathrm{ft}^{2}$ 
Figure 24 plots the slopes obtained from the linear regression of cooling energy use in the month of July vs area (from Figure 21) against the R-value of the insulating roof layer for the simulation performed in Phoenix, AZ. Slopes recorded from Figure 21 are reported in SI units in Figure 24.

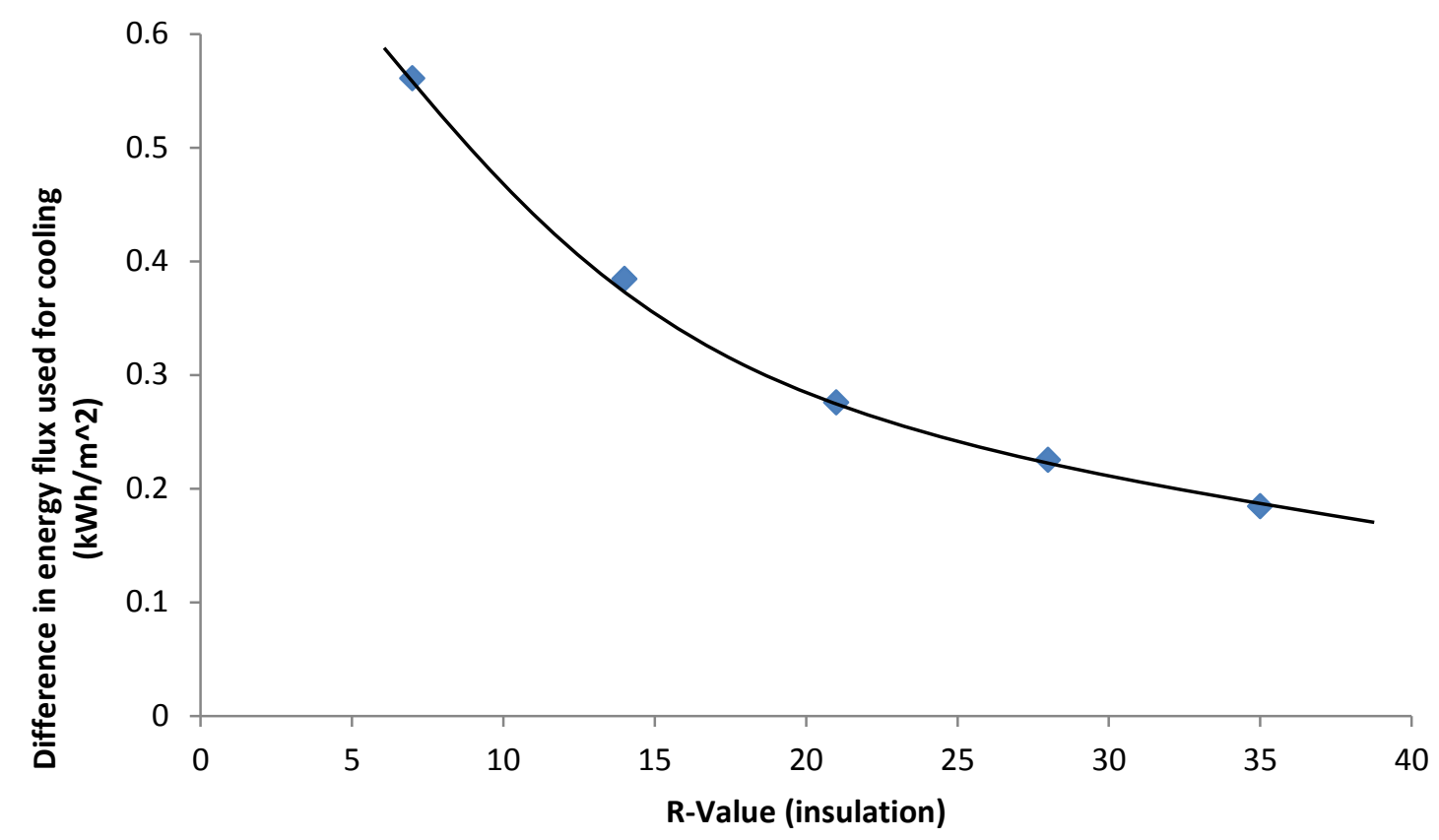

Figure 24: Difference in electricity consumed for cooling per unit area in July (dark roof simulation vs white roof simulation) plotted vs R-value (IP units). Building simulation was performed in Phoenix, AZ. 
Figure 25 plots the slopes obtained from the linear regression of annual cooling energy use vs area (from Figure 22) against the R-value of the insulating roof layer for the simulation performed in Phoenix, AZ. Slopes recorded from Figure 22 are reported in SI units in Figure 25. For less insulated buildings, the ratio between the annual flux and the total flux for July is approximately $5: 1$, this ratio decreases marginally when considering more well-insulated buildings, decreasing to a value of 5:1 when looking at a very well insulated roof.

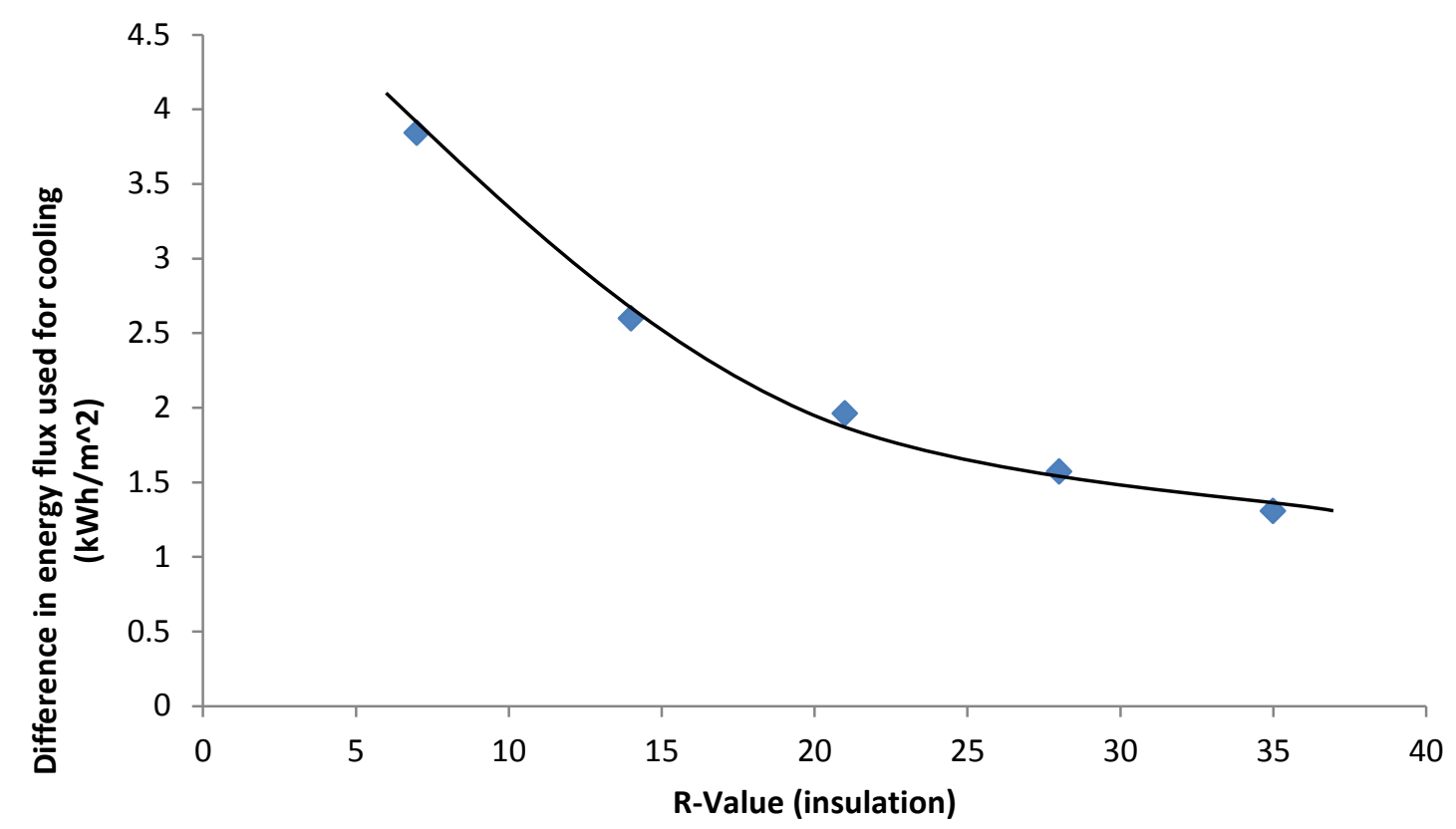

Figure 25: Difference in electricity consumed annually for cooling per unit area (dark roof simulation vs white roof simulation) plotted vs R-value (IP units). Building simulation was performed in Phoenix, AZ. 
Figure 26 plots the slopes obtained from the linear regression of annual heating energy use vs area (from Figure 23) against the R-value of the insulating roof layer for the building simulation performed in Phoenix, AZ. Slopes recorded from Figure 23 are reported in SI units in Figure 26. In this climate, the cooling energy savings flux significantly outweighs the heating energy penalty flux from replacing the dark roof with a white roof for a given insulation value.

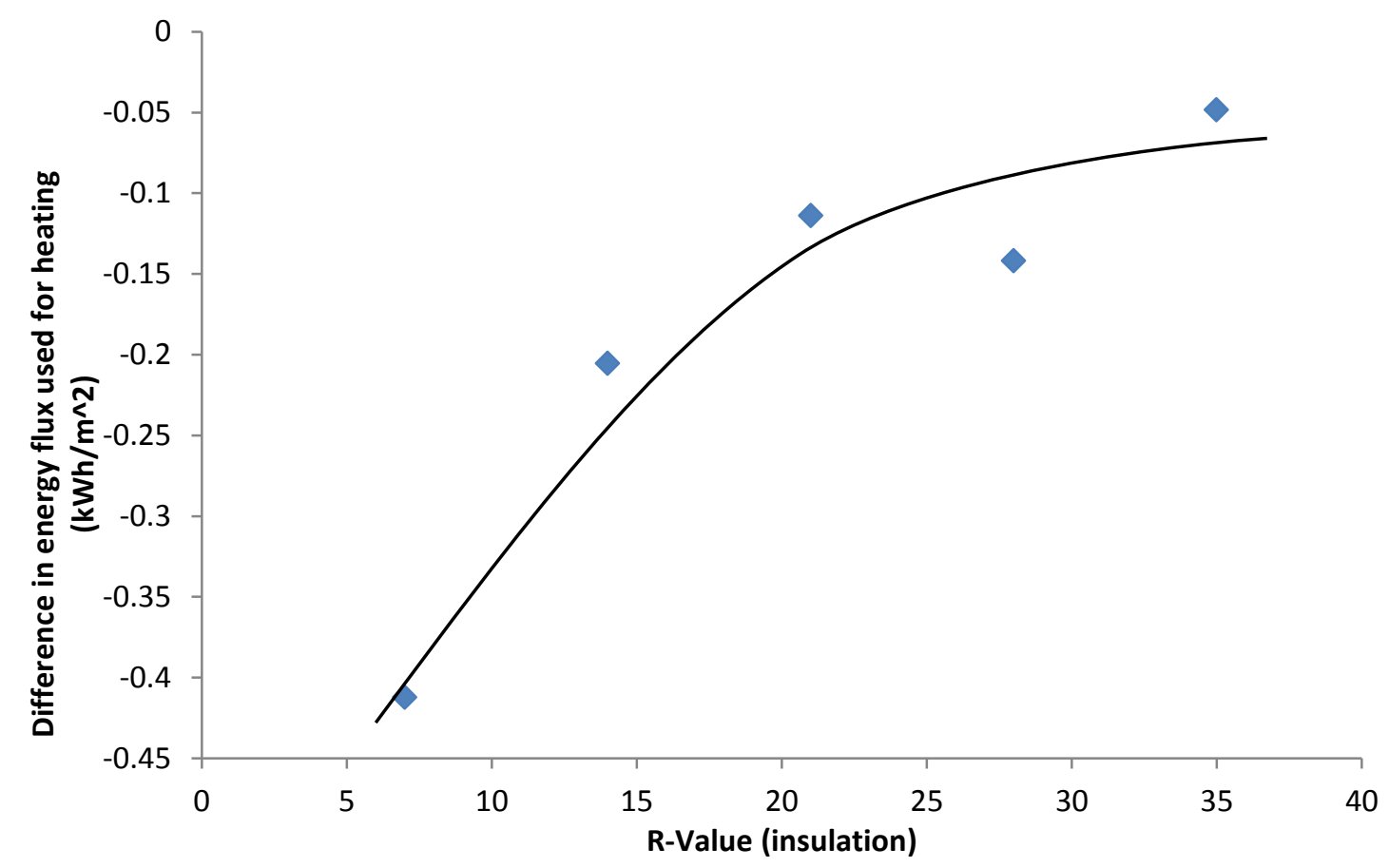

Figure 26: Difference in natural gas consumed annually for heating per unit area (dark roof simulation vs white roof simulation) plotted vs R-value (IP units). Building simulation was performed in Phoenix, AZ. 
Figure 27 plots the reduction in rooftop cooling load per unit area in the month of July as a function of the R-Value of the insulating material for Phoenix, AZ. This cooling load reduction flux is obtained from eQUEST by obtaining the linear regression of the cooling load reduction plotted against the roof area. Cooling load reduction is a minimum at R-35 of approximately $0.66 \mathrm{kWh} / \mathrm{m}^{2}$. From Figure 24, the cooling load energy savings at R-35 is $0.18 \mathrm{kWh} / \mathrm{m}^{2}$, a ratio of about $3.5: 1$.

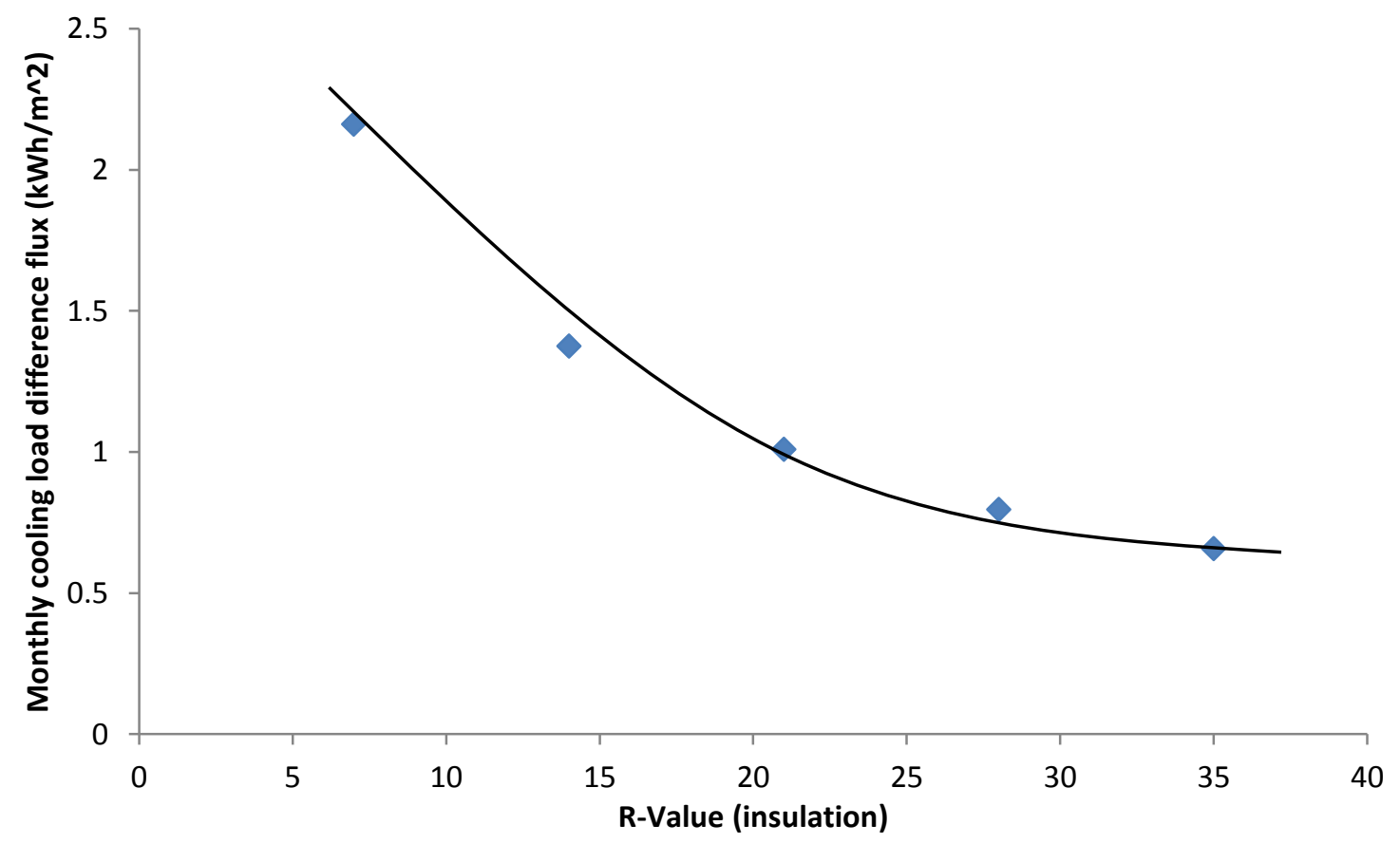

Figure 27: Difference in roof-top cooling load contribution per unit area for July (dark roof simulation vs white roof simulation) plotted vs R-value (IP units). Building simulation was performed in Phoenix, AZ. 
Figure 28 plots the reduction in annual rooftop cooling load per unit area as a function of the R-Value of the insulating material in Phoenix, AZ. This cooling load reduction flux is obtained from eQUEST by obtaining the linear regression of the cooling load reduction plotted agaisnt the roof area. Cooling load reduction is a minimum at R-35 of approximately $5.77 \mathrm{kWh} / \mathrm{m}^{2}$. From Figure 25, the cooling load energy savings at R-35 is $1.30 \mathrm{kWh} / \mathrm{m}^{2}$, a ratio of about $4: 1$.

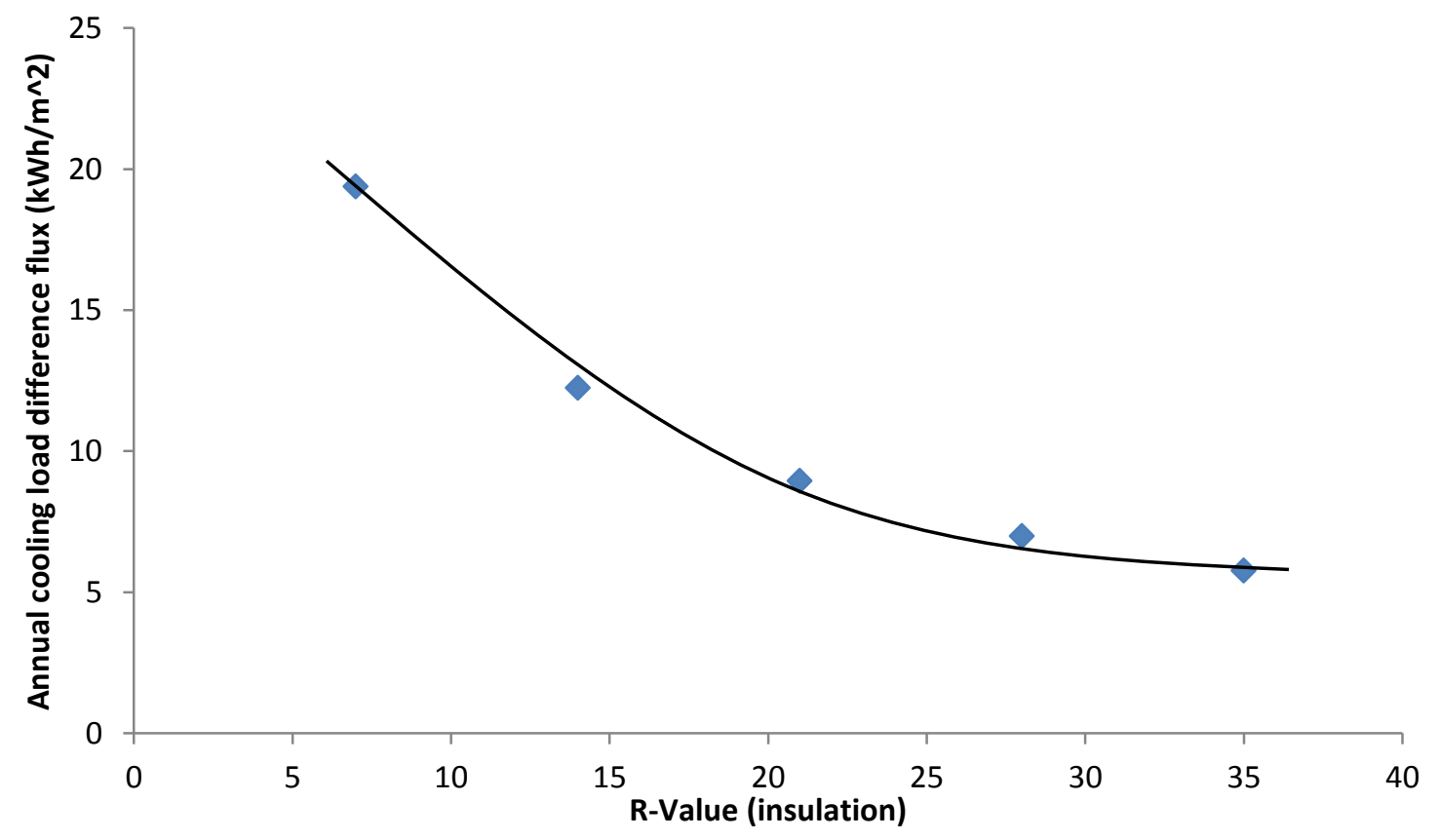

Figure 28: Difference in annual roof-top cooling load contribution per unit area (dark roof simulation vs white roof simulation) plotted vs R-value (IP units). Building simulation was performed in Phoenix, AZ. 
Figure 29 plots the the reduction in annual rooftop heating load per unit area as a function of the R-Value of the insulating material for the building simulation in Phoenix, AZ. Heat load reduction is a minimum (in magnitude) at $\mathrm{R}-35$ of approximately $-0.64 \mathrm{kWh} / \mathrm{m}^{2}$. The negative sign indicates that the rooftop heating load increases by going from a dark roof to a white roof. From Figure 26, the space heating energy savings at R-35 is -0.05 $\mathrm{kWh} / \mathrm{m}^{2}$, a ratio of about $12: 1$.

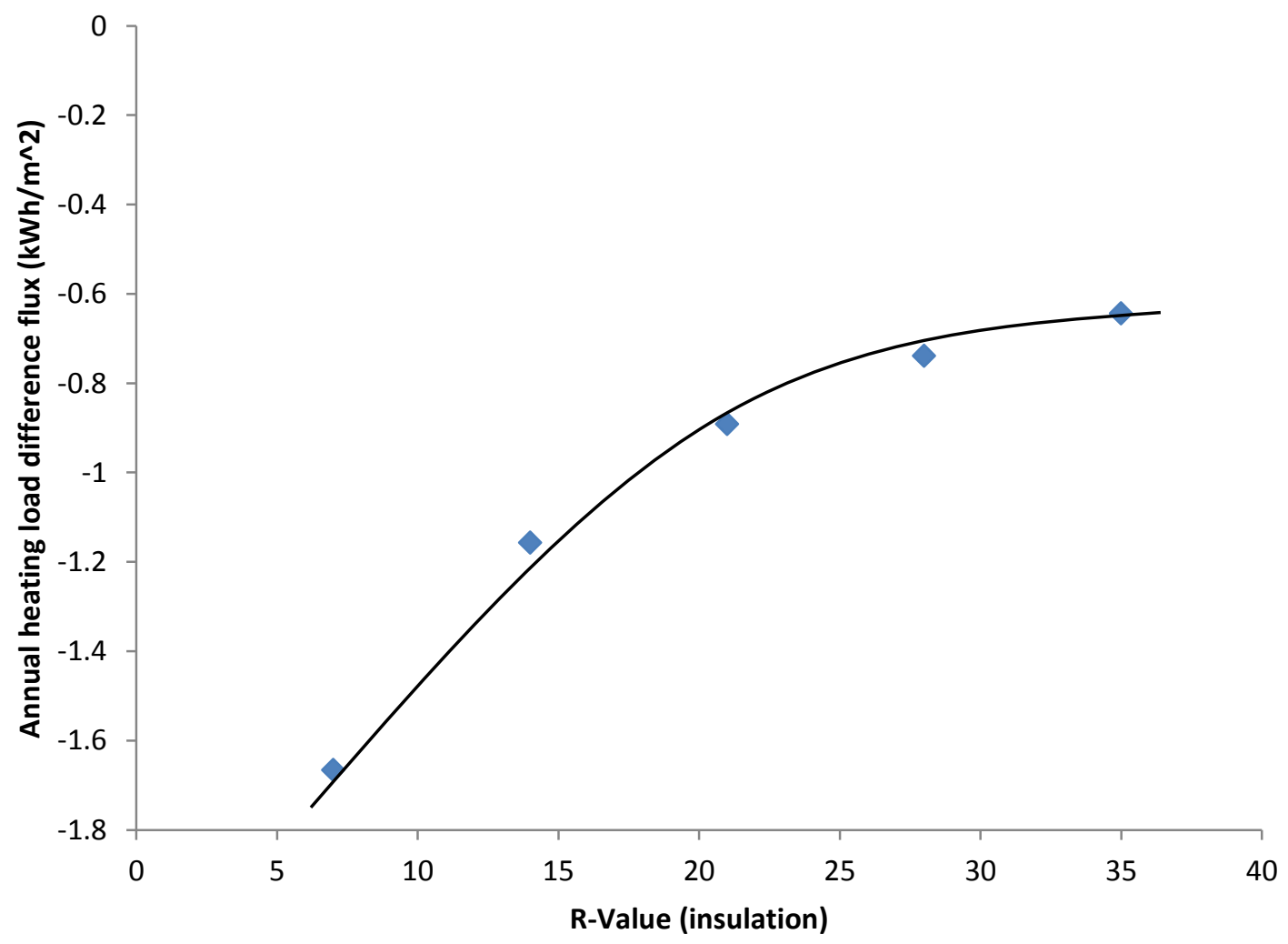

Figure 29: Difference in annual roof-top heating load contribution per unit area (dark roof simulation vs white roof simulation) plotted vs R-value (IP units). Building simulation was performed in Phoenix, AZ. 
Table 1: Comprehensive list of thermal load mitigation and end use energy savings in $\mathrm{kWh} / \mathrm{m}^{2}$ for building simulation in Portland, OR.

\begin{tabular}{|c|c|c|c|c|c|c|}
\hline \multirow{2}{*}{} & \multicolumn{2}{|c|}{ Thermal Loads $\left(\mathrm{kWh} / \mathrm{m}^{2}\right)$} & \multicolumn{3}{c|}{ Energy Use $\left(\mathrm{kWh} / \mathrm{m}^{2}\right)$} \\
\cline { 2 - 7 } & July & \multicolumn{2}{|c|}{ Annual } & July & \multicolumn{2}{c|}{ Annual } \\
\hline R-Value & Cooling & Cooling & Heating & Cooling & Cooling & Heating \\
\hline 7 & 1.95 & 9.45 & -3.55 & 0.44 & 1.67 & -1.43 \\
\hline 14 & 1.23 & 5.87 & -2.41 & 0.30 & 1.08 & -0.81 \\
\hline 21 & 0.90 & 4.23 & -1.85 & 0.22 & 0.87 & -0.55 \\
\hline 28 & 0.71 & 3.28 & -1.52 & 0.18 & 0.70 & -0.44 \\
\hline 35 & 0.58 & 2.66 & -1.31 & 0.15 & 0.58 & -0.38 \\
\hline
\end{tabular}

Table 1 presents a summary of results for the building simulation performed in Portland. These were presented in graphical form in order to emphasize the relationship between insulation value and difference in thermal load. The values represent the difference in thermal load and energy use between the dark roof simulation and the white roof simulation, and the use of negative signs emphasizes that over the course of a year, the white roof loses more energy from the building than the dark roof. Presented here in numeric form, the data shows that for each insulation value, the difference between the annual cooling savings and annual heating penalty associated with the white roof located in Portland is between $0.2-0.25 \mathrm{kWh} / \mathrm{m}^{2}$. 
Table 2: Ratio of Energy Use to Thermal Load, for cooling reduction in July, annual cooling reduction and heating penalty. Building simulation conducted in Portland, OR.

\begin{tabular}{|c|c|c|c|}
\hline \multirow{2}{*}{} & \multicolumn{2}{|c|}{ Energy Use - Thermal Load Ratio } \\
\cline { 2 - 4 } & July & \multicolumn{2}{c|}{ Annual } \\
\hline R-Value & Cooling & Cooling & Heating \\
\hline 7 & 0.22 & 0.18 & 0.40 \\
\hline 14 & 0.24 & 0.18 & 0.33 \\
\hline 21 & 0.25 & 0.20 & 0.30 \\
\hline 28 & 0.25 & 0.21 & 0.29 \\
\hline 35 & 0.26 & 0.22 & 0.29 \\
\hline
\end{tabular}

Table 2 presents the ratio between energy use and thermal load for the building simulation conducted in Portland, OR. The meaning of the cooling ratio is that for every additional unit of energy saved by replacing a dark roof with a white roof, the total roof contribution to cooling load is reduced by 4-5 units for the July data, and up to nearly 6 units for the annual results. The heating ratio implies that for every additional unit of energy consumed by replacing the dark roof with the white roof, an additional 2.5 to 3 units of energy are contributed to the heating load by switching from the dark to the white roof. 
Table 3: Comprehensive list of thermal load mitigation and end use energy savings in $\mathrm{kWh} / \mathrm{m}^{2}$ for building simulation in Phoenix, AZ.

\begin{tabular}{|c|c|c|c|c|c|c|}
\hline \multirow{2}{*}{} & \multicolumn{2}{|c|}{ Thermal Loads $\left(\mathrm{kWh} / \mathrm{m}^{2}\right)$} & \multicolumn{3}{c|}{ Energy Use $\left(\mathrm{kWh} / \mathrm{m}^{2}\right)$} \\
\cline { 2 - 7 } & July & \multicolumn{2}{|c|}{ Annual } & July & \multicolumn{2}{c|}{ Annual } \\
\hline R-Value & Cooling & Cooling & Heating & Cooling & Cooling & Heating \\
\hline 7 & 2.16 & 19.38 & -1.67 & 0.56 & 3.84 & -0.41 \\
\hline 14 & 1.38 & 12.25 & -1.16 & 0.38 & 2.60 & -0.21 \\
\hline 21 & 1.01 & 8.95 & -0.89 & 0.28 & 1.96 & -0.11 \\
\hline 28 & 0.80 & 7.00 & -0.74 & 0.22 & 1.57 & -0.14 \\
\hline 35 & 0.66 & 5.77 & -0.64 & 0.18 & 1.30 & -0.05 \\
\hline
\end{tabular}

Similar to Table 1, Table 3 presents a summary of results for the building simulation performed in Phoenix, AZ. Presented here in numeric form, the data shows that for each insulation value, the difference between the annual cooling savings and annual heating penalty associated with the white roof located in Phoenix is between $1.25-3.43 \mathrm{kWh} / \mathrm{m}^{2}$. 
Table 4: Ratio of Thermal Loads to Energy Use, for cooling reduction in July, annual cooling reduction and heating penalty. Building simulation conducted in Phoenix, AZ.

\begin{tabular}{|c|c|c|c|}
\hline \multirow{2}{*}{} & \multicolumn{2}{|c|}{ Thermal Loads-Energy Use Ratio } \\
\cline { 2 - 4 } & July & \multicolumn{2}{|c|}{ Annual } \\
\hline R-Value & Cooling & Cooling & Heating \\
\hline 7 & 0.26 & 0.20 & 0.25 \\
\hline 14 & 0.28 & 0.21 & 0.18 \\
\hline 21 & 0.27 & 0.22 & 0.13 \\
\hline 28 & 0.28 & 0.22 & 0.19 \\
\hline 35 & 0.28 & 0.23 & 0.08 \\
\hline
\end{tabular}

Table 4 presents the ratio between energy use and thermal load for the building simulation conducted in Phoenix, AZ. The meaning of the cooling ratio is that for every additional unit of energy saved by replacing a dark roof with a white roof, the total roof contribution to cooling load is reduced by 3-4 units for the July data, and up to nearly 5 units for the annual results. The heating ratio implies that for every additional unit of energy consumed by replacing the dark roof with the white roof, an additional 4 to 12 units of energy are contributed to the heating load by switching from the dark to the white roof. 


\section{Chapter 4: Discussion}

The heat flux data from the field experiment reveals that during the summer, the dark membrane roof has a peak heat flux gain of nearly $3-4 \mathrm{~W} / \mathrm{m}^{2}$ greater than the white membrane roof. Both dark and white roofs have heat gains during the day, but in the case of the dark roof the night time heat loss does not balance out the daytime heat gain. The difference in summer-time heat flux between the dark and white roof is nearly 0.9 $\mathrm{kWh} / \mathrm{m}^{2}$ for the month of July. Whereas in the summer, the black and white roof surface temperatures fluctuated about the interior ceiling temperature, in the winter, the temperature profiles for the four roofing alternatives reveal that during the analysis period the temperature of the interior ceiling remained higher than any of the roof temperatures. The black surface mitigates heat loss in winter time better than the white roof, as shown by the $0.09 \mathrm{kWh} / \mathrm{m}^{2}$ decrease in heat loss from the International Harvester Building extrapolated for the month of January, which is consistent with the white roof winter-time penalty reported in the literature.

In the field experiment, the white roof was shown to effectively alleviate heat gain during the summer week analysis period, which supports the findings in previous studies that white roofs can offer reduced summertime cooling loads compared to dark roofs. In winter-time, the black membrane roof outperforms the white membrane in reducing heating loads because the dark roof reflects a smaller quantity of incoming short-wave radiation than the other roofs. Thus the average flux associated with the dark roof is slightly larger than with the white roof, and as a result the net difference is very small compared to the total thermal load associated with the building. In spite of this, the study 
does provide some comprehensive indicators about the performance of various roofing systems, which may marginally improve energy savings in buildings.

The extrapolated cooling load flux associate with comparing the black and white surfaces of the international harvester building provides a target for numerical simulation. This target is associated with both the major building parameters controlling roof thermal loads and also understanding how the albedo of the roof can impact overall energy consumption for a stock building. As indicated in the first chapter, electricity use constituted nearly $73 \%$ of the total energy consumption associated with the building sector, therefore quantifying the reduction in end energy use associated with sustainable roofing technologies is very important. Extrapolating the international harvester data to other buildings, a stock building with a $1000 \mathrm{~m}^{2}$ roof would conceivably reduce cooling load by approximately $920 \mathrm{kWh}$ for the month of July, simply by replacing a dark membrane roof with a white membrane roof. However, the experimental results do not provide a clear picture of how much actual usable energy is saved by changing from a conventional dark roof to a white surface. Similarly, the experimental results indicate that the average winter-time penalty extrapolated over the whole month of January would result in a heating load flux increase of $0.089 \mathrm{kWh} / \mathrm{m}^{2}$ by switching from a black surface to a white surface. This would imply that the $1000 \mathrm{~m}^{2}$ building would see an added thermal load of $89 \mathrm{kWh}$ by switching from a black to white surface.

The motivation for the building simulation model was that a consistent parameter could be isolated from the analysis that could be related to multiple parameters. This parameter was isolated as the difference per unit area for each run between the dark roof and white roof, and was obtained by finding the slopes of the roof top thermal load vs 
area, and the slope of the total building energy use vs total area. One consistent trend with the plots of energy vs area was that all of the graphs involving roof contributions to coolign load had a perfect linear regression. However, the graphs involving energy consumption did not reveal an ideal linear regression, but had some residual error. The likely cause of this is that although as many variables were kept constant across simulations as possible, autosizing the chillers to match building area per the default design conditions for the thermostat in the stock building likely caused the energy consumption difference to vary from a perfectly linear regression. The presence of a nonzero y-intercept in the heating curve (Figures 14 and 23) indicates that for small buildings, the annual heating penalty associated with the white roof outweighs the cooling benefits provided by the white roof. However, as the slope of the cooling energy use curve is larger in magnitude than the slope of the heating energy use curve, as the building size increases, the cooling benefits approach and then eventually offset the winter-time heating penalty associated with the white roof at a large enough roof area.

Figure 16 shows that the annual savings for cooling energy use by switching from a dark surface to a white surface is on the order of $0.6 \mathrm{kWh} / \mathrm{m}^{2}$ for a well insulated building. The approximate ratio of annual cooling energy savings to July cooling energy savings is on the order of $4: 1$, which supports the conclusion that the white roof is more valuable for energy savings during the summer months in Portland.

The annual heating energy savings (Figure 17) are on the same order as the cooling savings, but there is a consistent offset between the cooling energy savings and the heating energy penalty which implies that for all insulation levels, the white roof provides a net benefit annually in Portland from the standpoint of energy savings. 
However, the net benefit is marginal, on the order of a fraction of a percent of the total energy consumption for a building.

Figure 18 shows the net cooling load difference flux in $\mathrm{kWh} / \mathrm{m}^{2}$ for the month of July in Portland. This particular graph is particulary important within the context of the experimental data, which produced an extrapolated value of $0.9 \mathrm{kWh} / \mathrm{m}^{2}$ for the difference in cooling load flux between the dark and white surfaces in the international harvester building. That corresponds to approximately an R-21 insulation material, with the caveat that the reflectivity of the white membrane on the international harvester is close to the reflectivity of the white built-up roofing material used in the simulation. Another run was conducted for R-35 insulation where the white roof was assumed to be glossy material with a very low absorptivity, and the cooling load flux savings was approximately $0.95 \mathrm{kWh} / \mathrm{m}^{2}$ for that run with R-35 material. However for the purposes of this analysis, it can be stated with confidence that the roof is well insulated, and that the extrapolated value for the experimental data is based on the assumption that the whole month of July 2012 would experience the same diurnal fluctuations as for the week of July 5-11, 2012. Thus the actual cooling load flux for the entire month is most probably a smaller quantity than $0.9 \mathrm{kWh} / \mathrm{m}^{2}$, indicating that the simulation results for cooling load are a reasonable estimation of real outcomes.

The small offset observed for the difference in cooling energy savings and the heating energy penalty is vastly different in the thermal load comparison for cooling and heating. The largest reduction in cooling load contribution per unit area is approximately $9 \mathrm{kWh} / \mathrm{m}^{2}$ (Figure 19, at R-7), whereas the maximum magnitude of the heating load penalty is approximately $3.5 \mathrm{kWh} / \mathrm{m}^{2}$ (Figure 20, at R-7). This correponds to an almost 
3:1 ratio between the cooling load reduction and the annual heating load penalty. However the practical question for this type of cost-benefit analysis lies in the actual energy savings of the HVAC system, which implies that for the Portland climate at the very least, the energy savings associated with implementing a white roof would not provide as much practical benefit as the cooling load reduction would imply. Coupled with the winter-time heating load penalty, and it is clear that the climate in Portland is not ideal for implementing a white roof, at least not for anything more than marginal energy savings.

The simulation results analyzing the implementation of the white roof in Phoenix, $\mathrm{AZ}$ were much more promising. The notable finding from these figures is that the difference between the annual results for Portland and Phoenix is much greater than the difference in the cooling energy savings for the month of July. The likely cause of this discrepancy is that for both Phoenix and Portland, July is part of the cooling season, which implies that the white roof provides no additional benefit during this month because in both climates, the white roof produces a cooling energy savings for July. However, Phoenix has much longer cooling seasons than Portland, and where the space cooling energy expenditure in Portland is negligible outside of 4-5 months out of the year, space cooling is important in Phoenix for many more months out of the year. Thus the white roof produces more significant savings for the Phoenix climate year-round, compared to Portland. The white roof energy savings for July in Phoenix are on the order of $0.2 \mathrm{kWh} / \mathrm{m}^{2}$ for a well insulated building. This goes up to $1.5 \mathrm{kWh} / \mathrm{m}^{2}$ for annual cooling savings (Figure 25), which is more than double the savings for the Portland climate (1.5 vs $0.6 \mathrm{kWh} / \mathrm{m}^{2}$ for R-35 insulation). This is even more magnified in Figure 
26, which shows the annual heating penalty for implementing a white roof in Phoenix. This is particularly significant because the annual heating penalty is much larger in Portland, which implies that installing a white roof in Phoenix is more appropriate than installing it in Portland. The data shown in Table 2 presents the ratio between actual energy consumption and thermal load for the building simulation performed in Portland, while Table 4 presents the same data for the building simulation performed in Phoenix. The COP of the chillers used for autosizing range from 2.8 for the smallest area, to 5.5 for the largest chiller. Although the July space cooling energy savings are not significantly different between the climates of Portland and Phoenix, the cooling energy savings were significant when considering the full year period of analysis. Yet Tables 2 and 4 show that the ratio of energy use to thermal loads is very similar between Portland and Phoenix, both for July and for the annual analysis. In July, the ratio is on the order of $.25-0.3$, whereas for annual cooling results, the ratio of energy use to thermal loads is on the order of 0.2-0.25. This is true for both simulations in Portland and in Phoenix. On the other hand, the space heating results were dramatically different between Portland and Phoenix. Where the ratio was on the order of 0.3-.4 for Portland, the ratio was on the order or $0.1-0.25$ for Phoenix. The implication of this ratio is that for every additional unit of heat load added due to the white roof penalty, the corresponding increase in actual energy expenditure is only 0.1-0.25 units in Phoenix, compared to 0.3-0.4 for Portland. 


\section{Chapter 5: Conclusions and Recommendations}

The focus of this research was on comprehensively analyzing how effectively white roofs mitigate thermal loads and consequently reduce space cooling requirements for buildings in Portland. In Portland, the simulation results from eQUEST indicate that using a white roof does not provide a significant advantage in terms of cooling energy savings. Although the roof thermal load analysis revealed significant reductions in heat flux through the roof, the actual space cooling demand for the stock building analyzed in Portland decreased only marginally within the context of the annual energy budget. Coupled with a significant winter heating penalty, the white roof does not perform particularly well in the Portland climate. On the other hand, the simulation results from the building in Phoenix, AZ revealed a substantial improvement in the performance of the white roof, not particularly surprising as the cooling energy demand is much larger in Phoenix. The white roof heating penalty was also much lower in Phoenix, which provides some clarity regarding how climate affects the performance of the white roof. To generalize these results, there are more substantial benefits on building energy use by implementing a white roof in a hot, dry climate like Phoenix, which falls in ASHRAE Zone $2 \mathrm{~B}$, as opposed to Portland which is classified as a mixed-marine environment (Zone 4C).

The findings that white roofs provide more substantial benefits in dry, hot climates like Phoenix is well known. However, a number of cool roof advocates utilize energy savings as a motivation for more large scale implementation of white roofing in urban centers around both the nation and in the world. As mentioned in the first chapter, 
the roofing selection process has more factors than just building energy impacts to consider. A major thrust for white roof implementation on a large scale is the documented effect of urban heat island reduction. Also, as noted in the plots showing energy savings per unit area versus roof insulation, white roofs can offer more substantial cooling savings benefits for poorly insulated buildings. Also, if the winter heat penalty is not a significant detraction in the decision-making process (as is often the case for buildings that use cheap natural gas), the low cost implementation of a white roof can provide immediate payback in the energy bill, even if is only a fractional reduction in savings.

Green roofs and solar photovoltaic (PV) panels can offer alternatives to a white roof when considering sustainable roofing alternatives. The impact on building energy savings of green roofs and shading with solar PV were excluded from the scope of the simulation, however their relative impact on thermal load was considered in the field experiment that was partially addressed in this report. To accurately quantify the impact of vegetated roofing as an alternative to conventional roofs or white roofs, the thermal mass of the vegetation and the latent evaporative effects must be factored into the energy balance, especially for irrigated green-roofs. This could be considered in future efforts to better characterize the benefits of implementing sustainable roofing technologies in Portland, OR. 


\section{References:}

1. Energy Efficiency and Renewable Energy. 2010. 2009 Buildings Energy Data Book. U.S. Department of Energy. http://buildingsdatabook.eere.energy.gov/

2. Annual energy review, EIA, Energy Information Administration (2007)

3. Michael, S, Where to live in the United States: combined energy demand for heating and cooling in the 50 largest metropolitan areas. Cities 2008; 25: p. 396-398

4. Bretz, S., H. Akbari, and A. Rosenfeld, Practical issues for using solar-reflective materials to mitigate urban heat islands. Atmospheric Environment, 1998. 32(1): p. 95-101.

5. Simpson, J.R. and E.G. McPherson, Effects of roof albedo modification on cooling loads of scale model residences in Tucson, Arizona. Energy and Buildings, 1997. 25(2): p. 127-137.

6. Taha, H., D. Sailor, and H. Akbari, High-Albedo Materials for Reducing Building Cooling Energy Use, 1992, Lawrence Berkeley Laboratory, University of California.

7. Taha, H., S. Konopacki, and S. Gabersek, Impacts of large-scale surface modifications on meteorological conditions and energy use: A 10-region modeling study. Theoretical and Applied Climatology, 1999. 62(3-4): p. 175-185.

8. Akbari, H., et al., Peak power and cooling energy savings of high-albedo roofs. Energy and Buildings, 1997. 25(2): p. 117-126.

9. Kolokotroni, M., B.L. Gowreesunker, and R. Giridharan, Cool roof technology in London: An experimental and modelling study. 2011.

10. Jo, J.H., et al., An integrated empirical and modeling methodology for analyzing solar reflective roof technologies on commercial buildings. Building and Environment, 2010. 45(2): p. 453-460.

11. Bretz, S., H. Akbari, Long-term performance of high albedo roof coatings. Journal Energy and Buildings, 1997. 25: p. 159-167

12. Rosenfeld, A.H., H. Akbari, M. Pomerantz, H. Taha, J. Romm, Policies to reduce heat islands: magnitudes of benefits and incentives to achieve them. Proceedings of the 1996 ACEEE Summer Study on Energy Efficiency in Buildings, vol. 9

13. Synnefa, A., M. Santamouris, I. Livada, A study of the thermal performance of reflective coatings for the urban environment. Journal of Solar Energy, 2006. 80: p. 968-981

14. Castleton, H.F., et al., Green roofs; building energy savings and the potential for retrofit. Energy and Buildings, 2010. 42: p. 1582-1591.

15. Jaffal, I., S., E. Ouldboukhitine, and R. Belarbi, A comprehensive study of the impact of green roofs on building energy performance. Renewable Energy, 2012. 43: p. 157164.

16. Sailor, D.J., A green roof model for building energy simulation programs. Energy and Buildings, 2008. 40(8): p. 1466-1478.

17. Sailor, D.J. and M. Hagos, An updated and expanded set of thermal property data for green roof growing media. Energy and Buildings, 2011. 43(9): p. 2298-2303. 
18. Theodosiou, T., Green roofs in buildings: Thermal and environmental behaviour. Advances in Building Energy Research, 2009. 3(1): p. 271-288.

19. Spolek, G. Performance monitoring of three ecoroofs in Portland, Oregon. Urban Ecosystems. 2008. 11, 349-359

20. Niachou, A., et al., Analysis of the green roof thermal properties and investigation of its energy performance. Energy and Buildings, 2001. 33(7): p. 719-729.

21. Golden, J.S., et al., A comparative study of the thermal and radiative impacts of photovoltaic canopies on pavement surface temperatures. Solar Energy, 2007. 81(7): p. 872-883.

22. Tian, W., et al., Effect of building integrated photovoltaics on microclimate of urban canopy layer. Building and Environment, 2007. 42(5): p. 1891-1901.

23. Scherba, A., et al., Modeling impacts of roof reflectivity, integrated photovoltaic panels and green roof systems on sensible heat flux into the urban environment. Building and Environment, 2011. 46: p. 2542-2551.

24. Shariah, A., B. Shalabi, A. Rousan, B. Tashtoush, Effects of absorptance of external surfaces on heating and cooling loads of residential buildings in Jordan, Energy Conversion and Management, 1998. 39: p. 273-284

25. Konopacki, S., H. Akbari, Simulated Impact of Roof Surface Solar Absorptance, Attic and Duct Insulation on Cooling and Heating Energy in Single Family New Residential Buildings. LBNL Report 41834, Berkeley, CA, 1998.

26. Cheung, C.K., R.J. Fuller, M.B. Luther, Energy efficient envelope design for high rise apartments, Energy and Buildings. 2005. 37(1): p. 37-48.

27. Miller, W.A., A.O. Desjarlais, H. Akbari, R. Levinson, P. Berdahl, R.G. Scichili, Special IR reflective pigments make a dark roof reflect almost like a white roof, Thermal Performance of the Exterior Envelopes of Buildings, IX, in Progress for Proceedings of ASHRAE THERM IX, Clearwater, FL, 2004.

28. Cheng, V., B. Givoni, Effect of envelope color and thermal mass on indoor temperatures in hot humid climate. Solar Energy, 2005 78: p. 528-534

29. Synnefa, A., M. Santamouris, H. Akbari, Estimating the effect of using cool coatings on energy loads and thermal comfort in residential buildings in various climatic conditions. Journal of Energy and Buildings, 2007. 39: p. 1167-1174

30. Berdahl, P., S. Bretz, 1997. Preliminary survey of the solar reflectance of cool roofing materials. Journal of Energy and Buildings, 1997. 25: p. 149-158

31. Prado, R., F.L. Ferreira, Measurement of albedo and analysis of its influence the surface temperature of building roof materials. Journal of Energy and Buildings, 2005. 37: p. 295-300

32. Waddell, C, S. Kaserekar. Solar gain and cooling load comparison using energy modeling software. Proceedings of SimBuild, 2010. New York City, NY. IBPSA-USA 